\title{
Recombinant mouse cytomegalovirus expressing a ligand for the NKG2D receptor is attenuated and has improved vaccine properties
}

\author{
Irena Slavuljica,1 Andreas Busche,2 Marina Babić,1 Maja Mitrović, ${ }^{1}$ Iva Gašparović, 1 \\ Đurđica Cekinović, ${ }^{1}$ Elitza Markova Car, ${ }^{1}$ Ester Pernjak Pugel, ${ }^{1}$ Ana Ciković, ${ }^{1}$ Vanda Juranić Lisnić, ${ }^{1}$ \\ William J. Britt,, ${ }^{3}$ Ulrich Koszinowski,4 Martin Messerle,,2 Astrid Krmpotić, ${ }^{1}$ and Stipan Jonjić1 \\ 1Department of Histology and Embryology, Faculty of Medicine, University of Rijeka, Rijeka, Croatia. 2Department of Virology, Hannover Medical School, \\ Hannover, Germany. ${ }^{3}$ Departments of Pediatrics, University of Alabama at Birmingham, Birmingham, Alabama, USA. ${ }^{4}$ Max von Pettenkofer-Institut, \\ Ludwig-Maximilians-Universität, Munich, Germany.
}

\begin{abstract}
Human CMV (HCMV) is a major cause of morbidity and mortality in both congenitally infected and immunocompromised individuals. Development of an effective HCMV vaccine would help protect these vulnerable groups. NK group 2, member D (NKG2D) is a potent activating receptor expressed by cells of the innate and adaptive immune systems. Its importance in HCMV immune surveillance is indicated by the elaborative evasion mechanisms evolved by the virus to avoid NKG2D. In order to study this signaling pathway, we engineered a recombinant mouse CMV expressing the high-affinity NKG2D ligand RAE-1 $\gamma(R A E-1 \gamma M C M V)$. Expression of RAE- $1 \gamma$ by MCMV resulted in profound virus attenuation in vivo and lower latent viral DNA loads. $R A E-1 \gamma \mathrm{MCMV}$ infection was efficiently controlled by immunodeficient hosts, including mice lacking type I interferon receptors or immunosuppressed by sublethal $\gamma$-irradiation. Features of MCMV infection in neonates were also diminished. Despite tight innate immune control, $R A E-1 \gamma M C M V$ infection elicited strong and long-lasting protective immunity. Maternal $R A E-1 \gamma M C M V$ immunization protected neonatal mice from MCMV disease via placental transfer of antiviral Abs. Despite strong selective pressure, the $R A E-1 \gamma$ transgene did not exhibit sequence variation following infection. Together, our results indicate that use of a recombinant virus encoding the ligand for an activating NK cell receptor could be a powerful approach to developing a safe and immunogenic HCMV vaccine.
\end{abstract}

\section{Introduction}

Human CMV (HCMV) is an important human pathogen causing morbidity and mortality in congenitally infected and immunosuppressed individuals. CMVs are highly adapted to their mammalian hosts and are host species-specific in their replication, which precludes the study of HCMV in animal models. Research on murine CMV (MCMV) is the most advanced model with regard to the principles that govern the immune surveillance of CMVs. After primary infection, the host immune response effectively terminates virus replication; however, clearance of the viral genome is not achieved, and CMV establishes lifelong latency, with periodic reactivation and shedding of virus (1).

While HCMV infection is readily controlled by the immunocompetent host, the virus displays its pathogenic potential when host immunity is impaired. HCMV infection is the most common viral congenital infection and may result in lifelong neurological sequelae, including brain damage, sensorineural hearing loss, and mental retardation (2-5). Solid organ transplant recipients and hematopoietic stem cell transplant recipients are the second group of patients at risk for severe CMV infections (6-8). In HIV-infected

Authorship note: Irena Slavuljica and Andreas Busche contributed equally to this work. Martin Messerle, Astrid Krmpotic, and Stipan Jonjic are co-senior authors. Conflict of interest: The authors have declared that no conflict of interest exists. Citation for this article: J Clin Invest. 2010;120(12):4532-4545. doi:10.1172/JCI43961. patients, CMV continues to be the most frequent viral opportunistic pathogen, although severe infections have become less common following the introduction of highly active antiretroviral therapy (9). Due to this immense public health challenge, the development of an HCMV vaccine has been ranked as a top priority for the 21st century by the U.S. Institute of Medicine (10).

Both innate and adaptive immune responses are important for the control of CMV infection (11-15). Innate immunity, in particular NK cells, plays a key role in limiting CMV infection at an early stage and in priming of the adaptive immune response $(16,17)$. $\mathrm{CD}^{+} \mathrm{T}$ cells are the principal effectors required for resolution of productive infection and establishment of latency (18). Although $\mathrm{CD}^{+} \mathrm{T}$ cells play a dominant role, $\mathrm{CD}^{+} \mathrm{T}$ cells and NK cells contribute to the maintenance of latent CMV infection (19). Antiviral Abs, although not essential for the control of primary CMV infection and the establishment of latency, play a critical role in limiting the dissemination of recurrent virus (20). Abs can modify the disease associated with HCMV infection in transplant recipients as well as congenital CMV infection in humans and experimental animal models (21-26). Consequently, a CMV vaccine should ideally aim to elicit an effective cellular and humoral immune response.

A number of subunit vaccine strategies and live, attenuated CMV vaccines have been developed (27-31). Recently, a phase II clinical trial was described that suggested a protective capacity against maternal infection by use of recombinant monovalent gB HCMV 
vaccine (32). While subunit vaccines induce an immune response to selected viral proteins, the advantage of live vaccines is that they elicit an immune response that mimics natural immunity and provides broader protection. Their use, however, carries the risk of CMV disease caused by the vaccine strain or reactivation in the immunocompromised state, unless the vaccine virus is efficiently controlled by residual immunity. One approach to generating such an immunogenic, yet safe live vaccine is deletion of viral genes that subvert the host immune response $(33,34)$ or essential genes resulting in spread-deficient virus (31). The other approach is the insertion of a ligand recognized by the activating receptor on immune cells into the CMV genome. In our study, we have used the latter approach and designed an experimental CMV vaccine encoding a ligand for NK group 2, member D (NKG2D), an activating receptor expressed on NK cells, activated $\mathrm{CD}^{+} \mathrm{T}$ cells, and $\gamma \delta$ T cells $(35,36)$. The engagement of NKG2D can override inhibitory signals delivered by self-MHC class I proteins and trigger NK cell activation. NKG2D binds to a family of MHC class Irelated proteins that are not constitutively expressed but are induced by cell transformation or stress, including infection. In mice, the RAE- 1 family of proteins, H60, and MULT- 1 are ligands for NKG2D. The importance of the NKG2D signaling pathway in CMV control is best illustrated by a sophisticated mechanism that HCMV and MCMV have developed to avoid NKG2D-mediated immune control. Four MCMV genes are dedicated to downmodulating all of the NKG2D ligands from the surface of infected cells: $m 152$ targets the RAE- 1 family of molecules; $m 145$ targets MULT-1; and $m 155$ targets H60. MULT-1, H60, and RAE- $1 \varepsilon$ are additionally downregulated by $m 138(37,38)$. The MCMV mutants lacking any of the NKG2D inhibitors are sensitive to the NK cell control in vivo, due to the preserved NKG2D ligand on the cell surface of infected cells (39). Similarly, HCMV encodes proteins that downregulate NKG2D ligands in humans (40).

To take the advantage of this powerful signaling pathway in the generation of a safe, yet immunogenic vaccine, we inserted RAE- $1 \gamma$ into the MCMV genome in place of the $m 152$ gene, which otherwise negatively regulates this NKG2D ligand. We hypothesized that (a) the deletion of $m 152$ from the MCMV genome should prevent downregulation of both endogenous RAE- $1 \gamma$ and RAE- $1 \gamma$ encoded by the transgene; and (b) the consistent expression of RAE- $1 \gamma$ on infected cells may override the effect of all other MCMV immunoevasins for NK cells and (c) may also augment the CD8 ${ }^{+}$ $\mathrm{T}$ cell response through the costimulatory function of NKG2D on these cells. Furthermore, since $\mathrm{m} 152$ additionally arrests the maturation of MHC class I molecules (41), the deletion of this gene may improve the presentation of viral proteins and enhance the $\mathrm{T}$ cell immune response. Here we demonstrate that RAE- $1 \gamma$ expressing MCMV (RAE-1 $\gamma \mathrm{MCMV})$ was dramatically attenuated in vivo not only in the immunocompetent host but even in immunological immature neonatal and in immunodeficient mice. However, despite tight immune control, RAE-1 $\gamma \mathrm{MCMV}$ infection elicited a potent, long-lasting cellular and $\mathrm{Ab}$ immune response able to protect animals against challenge infection. Moreover, maternal $R A E-1 \gamma \mathrm{MCMV}$ infection resulted in the production and placental transfer of antiviral Abs that protected offspring from MCMV infection following neonatal infection.

\section{Results}

Generation and in vitro characterization of a recombinant MCMV expressing the NKG2D ligand RAE- $1 \gamma$. To study how the expression of NKG2D ligand by MCMV influences immunobiology of this virus infection, we designed a recombinant virus, referred to as $R A E-1 \gamma \mathrm{MCMV}$, that expresses RAE- $1 \gamma$. RAE- $1 \gamma \mathrm{MCMV}$ was constructed by replacing the $\mathrm{m} 152 \mathrm{ORF}$ in the (BAC-cloned) MCMV genome with a cassette comprising the RAE- $1 \gamma$ ORF under control of the HCMV immediateearly promoter (Figure 1A). RAE-1 $\gamma \mathrm{MCMV}$ replication assessed in a multistep growth kinetics assay was comparable to WT MCMV replication (Supplemental Figure 1A; supplemental material available online with this article; doi:10.1172/JCI43961DS1). Infection of SVEC4-10 cells, an endothelial cell line that does not express RAE- $1 \gamma$, with the recombinant MCMV resulted in cell surface RAE- $1 \gamma$ expression (Figure 1B). As shown previously, WT MCMV infection downregulates endogenous RAE- $1 \gamma$, which was prevented by the deletion of $m 152$ from the MCMV genome ( $\triangle m 152 \mathrm{MCMV})$. Introduction of RAE- $1 \gamma$ to the $\triangle m 152 \mathrm{MCMV}$ resulted in RAE- $1 \gamma$ overexpression on the surface of infected MEFs and NIH 3 T3 cells (Figure $1 B)$. Note that $R A E-1 \gamma \mathrm{MCMV}$ infection did not change the pattern of cell surface expression of other NKG2D ligands compared with $\Delta m 152$ MCMV (Supplemental Figure 1B). Together, these data indicate that $R A E-1 \gamma$ insertion into the MCMV genome had no effect on virus replication in vitro and resulted in the expression of RAE- $1 \gamma$ on the surface of infected cells.

RAE- $1 \gamma M C M V$ is strongly attenuated in vivo and fails to establish persistent infection in salivary gland. Adult $\mathrm{BALB} / \mathrm{c}$ mice were injected with $R A E-1 \gamma \mathrm{MCMV}$, WT MCMV, or $\Delta m 152 \mathrm{MCMV}$ to study whether expression of the NKG2D ligand by the MCMV influences virus control in vivo. In agreement with our previous results (42), at day 3 after infection (day 3 p.i.) replication of $\Delta m 152$ MCMV was attenuated in an NKG2D-dependent manner as compared with WT MCMV. Introduction of RAE- $1 \gamma$ into the $\triangle m 152 \mathrm{MCMV}$ genome further attenuated viral replication and resulted in significantly lower viral titers in all tested organs as compared with $\Delta m 152 \mathrm{MCMV}$ and WT MCMV (Figure 1C). The observed attenuation was NKG2D-dependent and was abolished by administration of anti-NKG2D blocking Abs that restored $R A E-1 \gamma \mathrm{MCMV}$ titers almost to the WT MCMV level.

The salivary glands remain persistently infected with MCMV long after productive virus replication is terminated in other tissues $(43,44)$. NK cells and $\mathrm{CD}^{+}{ }^{+} \mathrm{T}$ cells are essential for virus clearance in the salivary glands and prevention of horizontal virus spread $(44,45)$. We therefore compared the virus titers in salivary glands 15,60 , and 150 days after RAE-1 $\gamma \mathrm{MCMV}$, WT MCMV, and $\Delta m 152 \mathrm{MCMV}$ infection. In contrast to a high-titer persistent virus replication in WT MCMV-infected mice, no infectious virus was detected in salivary glands following RAE- $1 \gamma \mathrm{MCMV}$ infection (Figure 1D). Although $\triangle m 152 \mathrm{MCMV}$ reached slightly lower virus titers compared with WT MCMV, replication kinetics of these two viruses in salivary glands were similar. We next determined whether marked differences between RAE- $1 \gamma \mathrm{MCMV}$ and WT MCMV replication are reflected in the kinetics of viral clearance from blood and viral genome load in tissue during latency. Unlike in mice infected with WT MCMV, in which viral DNA was maintained in the blood for prolonged period of time (46), viral DNA was cleared from the blood of RAE-1 $\gamma \mathrm{MCMV}$-infected mice by day 45 . At that time, RAE-1 $\gamma \mathrm{MCMV}$ DNA remained in organs, but the viral load was reduced to a barely detectable level or, in some cases, to below the limit of detection. Viral DNA load in $\Delta m 152 \mathrm{MCMV}$-infected mice corresponded to infectious virus titers (Figure 1E).

To study how the expression of NKG2D ligand by the MCMV affects virus control in mice with a constitutively more efficient 
A MCMV

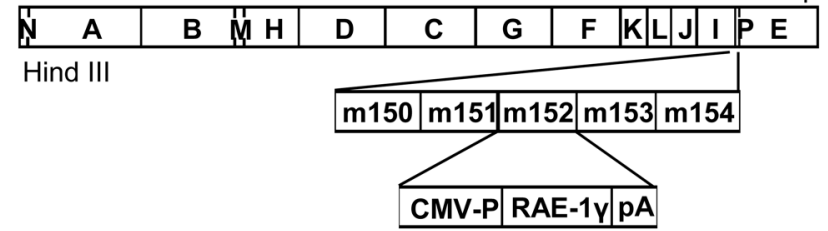

B

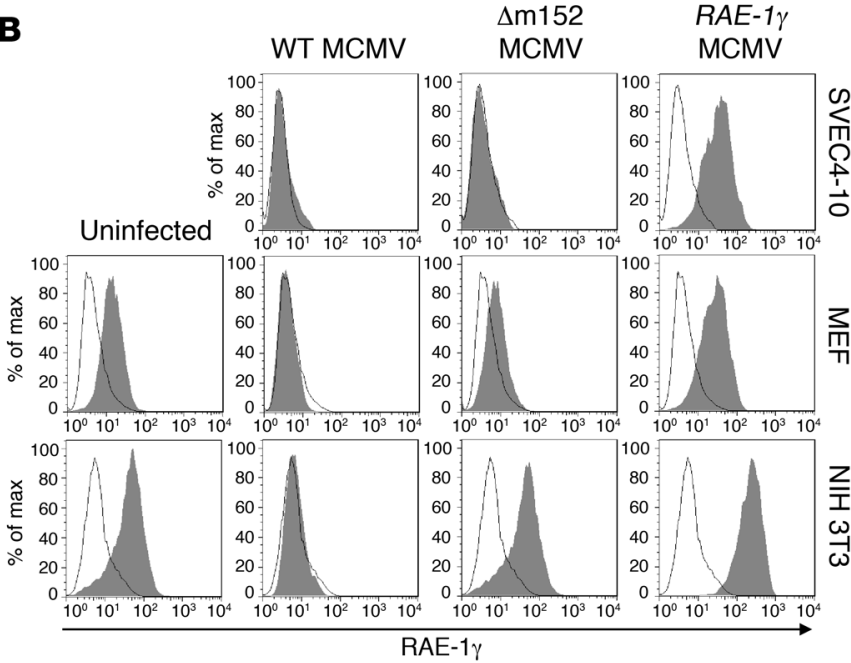

c

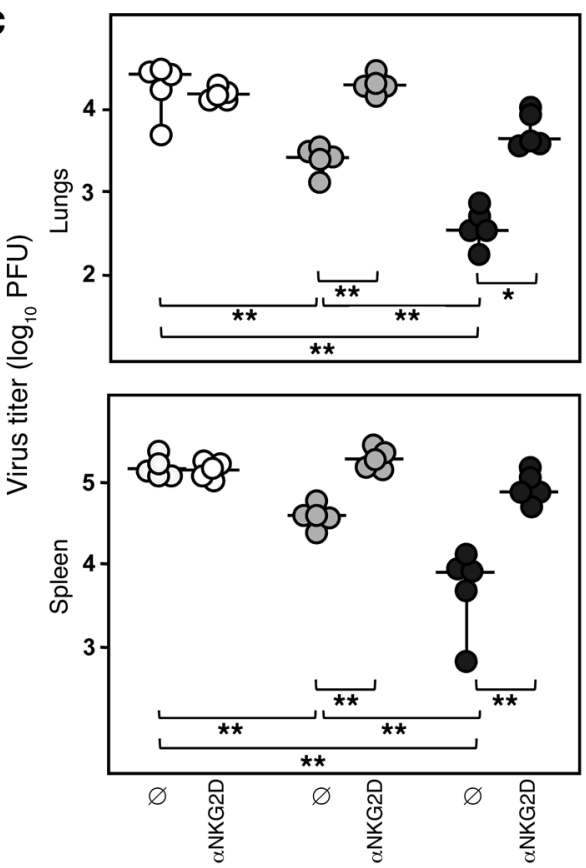

D

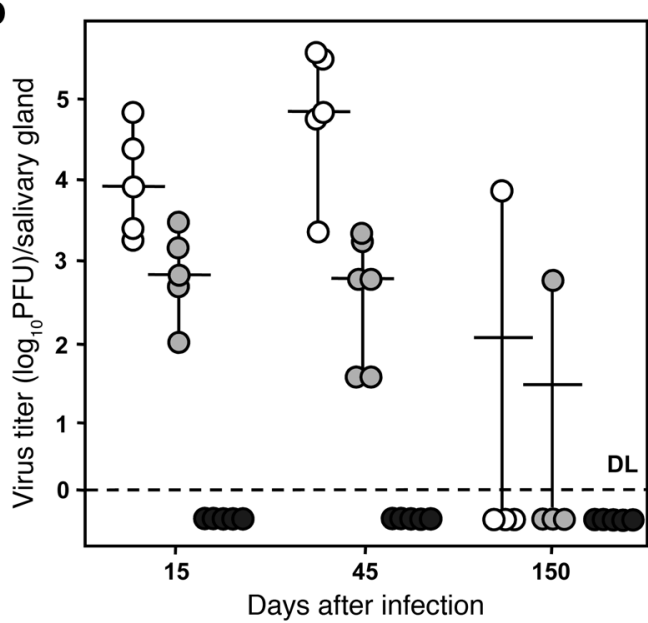

E

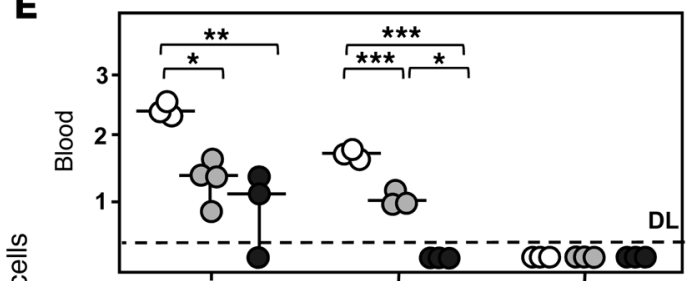

O WT MCMV

O $\triangle m 152 M C M V$

RAE-1 $\gamma \mathrm{MCMV}$

Figure 1

$R A E-1 \gamma \mathrm{MCMV}$ is attenuated in vivo in an NKG2D-dependent manner. (A) The Hindlll cleavage map of the MCMV genome is shown at the top, with the genomic region encoding the m152 ORF below. The 152 ORF was replaced by an expression cassette (bottom) comprising the HCMV major immediate early promoter (CMV-P), the RAE-1 $\gamma$ ORF, and the SV40 polyadenylation signal sequence. (B) SVEC4-10 cells, NIH 3T3 cells, and MEFs were infected with the indicated viruses and 12 hours later analyzed for the surface expression of RAE-1 $\gamma$ by staining with anti-RAE-1 $\gamma$ $A b$, followed by PE-conjugated goat anti-rat IgG. Cells incubated with the secondary $A b$ in the absence of the primary Ab were used as negative control (thin line). Each histogram represents 10,000 gated propidium iodide-negative cells. (C) Untreated BALB/c mice or BALB/c mice treated with blocking anti-NKG2D mAb were i.v. injected with $10^{5} \mathrm{PFU}$ of the indicated viruses. Viral titers were determined in lungs and spleen 3 days p.i. by plaque assay. $\varnothing$, untreated BALB/c mice. (D) BALB/c mice were f.p. injected with $2 \times 10^{5}$ PFU of the indicated viruses. Viral titers were determined by plaque assay and (E) viral genome load by qPCR at different time p.i. Individual mice (circles) and median values (horizontal bars) are shown. DL, detection limit. Results from 1 of 2 similar experiments are shown. ${ }^{\star} P<0.05,{ }^{* \star} P<0.01,{ }^{\star \star \star} P<0.001$. 

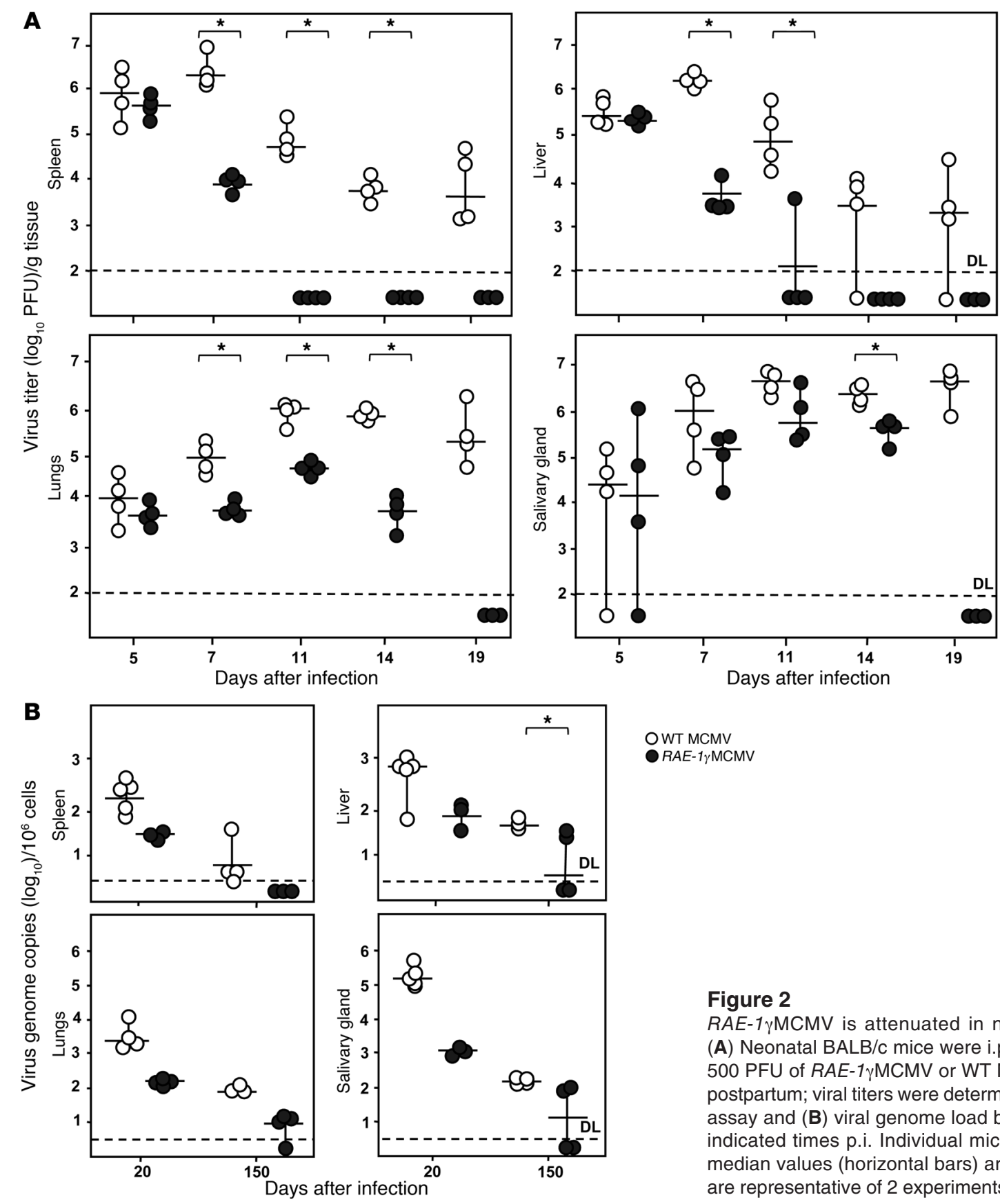

OWT MCMV

RAE- $1 \gamma \mathrm{MCMV}$

Figure 2

$R A E-1 \gamma \mathrm{MCMV}$ is attenuated in neonatal mice. (A) Neonatal BALB/c mice were i.p. injected with 500 PFU of RAE-1 $\gamma \mathrm{MCMV}$ or WT MCMV 6 hours postpartum; viral titers were determined by plaque assay and (B) viral genome load by qPCR at the indicated times p.i. Individual mice (circles) and median values (horizontal bars) are shown. Data are representative of 2 experiments. ${ }^{*} P<0.05$.

NK cell response, we injected C57BL/6 with RAE-1 $\gamma \mathrm{MCMV}$, WT $\mathrm{MCMV}$, or $\triangle m 152 \mathrm{MCMV}$. MCMV resistance of C57BL/6 mice is due to the expression of Ly $49 \mathrm{H}$ activating receptor on NK cells, which recognizes virally encoded protein $\operatorname{m} 157(47,48)$. Similar to results in MCMV-sensitive BALB/c mice, RAE- $1 \gamma \mathrm{MCMV}$ reached significantly lower titers compared with WT MCMV and $\triangle m 152 \mathrm{MCMV}$. Thus, unlike in mice infected with MCMV mutant lacking $m 152$ only, NKG2D-mediated control of RAE$1 \gamma \mathrm{MCMV}$ was not overcome by NK cell activation via Ly49H (Supplemental Figure 2A). Taken together, the results indicate that expression of RAE- $1 \gamma$ by MCMV resulted in a dramatic attenuation of virus replication in different organs and a lower latent viral DNA load.
RAE- $1 \gamma M C M V$ is attenuated even in neonatal mice. Neonatal mice are highly sensitive to MCMV infection, and i.p. injection even with a low dose of cell culture-derived virus results in significant morbidity and mortality. Mice that survive MCMV infection establish a disseminated, high-titer virus replication and long-lasting persistent infection in salivary glands (43). To test RAE- $1 \gamma \mathrm{MCMV}$ replication in neonatal mice, we injected newborn animals i.p. with 500 PFU of RAE- $1 \gamma \mathrm{MCMV}$ or WT MCMV. During the first 5 days of infection, the two viruses replicated to comparable titers, but starting from day 7 RAE- $1 \gamma \mathrm{MCMV}$ replication was significantly reduced in all tested organs (Figure $2 \mathrm{~A}$ ). Productive $R A E-1 \gamma \mathrm{MCMV}$ infection was cleared by day 11 in spleen and liver and by day 19 in lungs and even in salivary glands. By contrast, around that time 

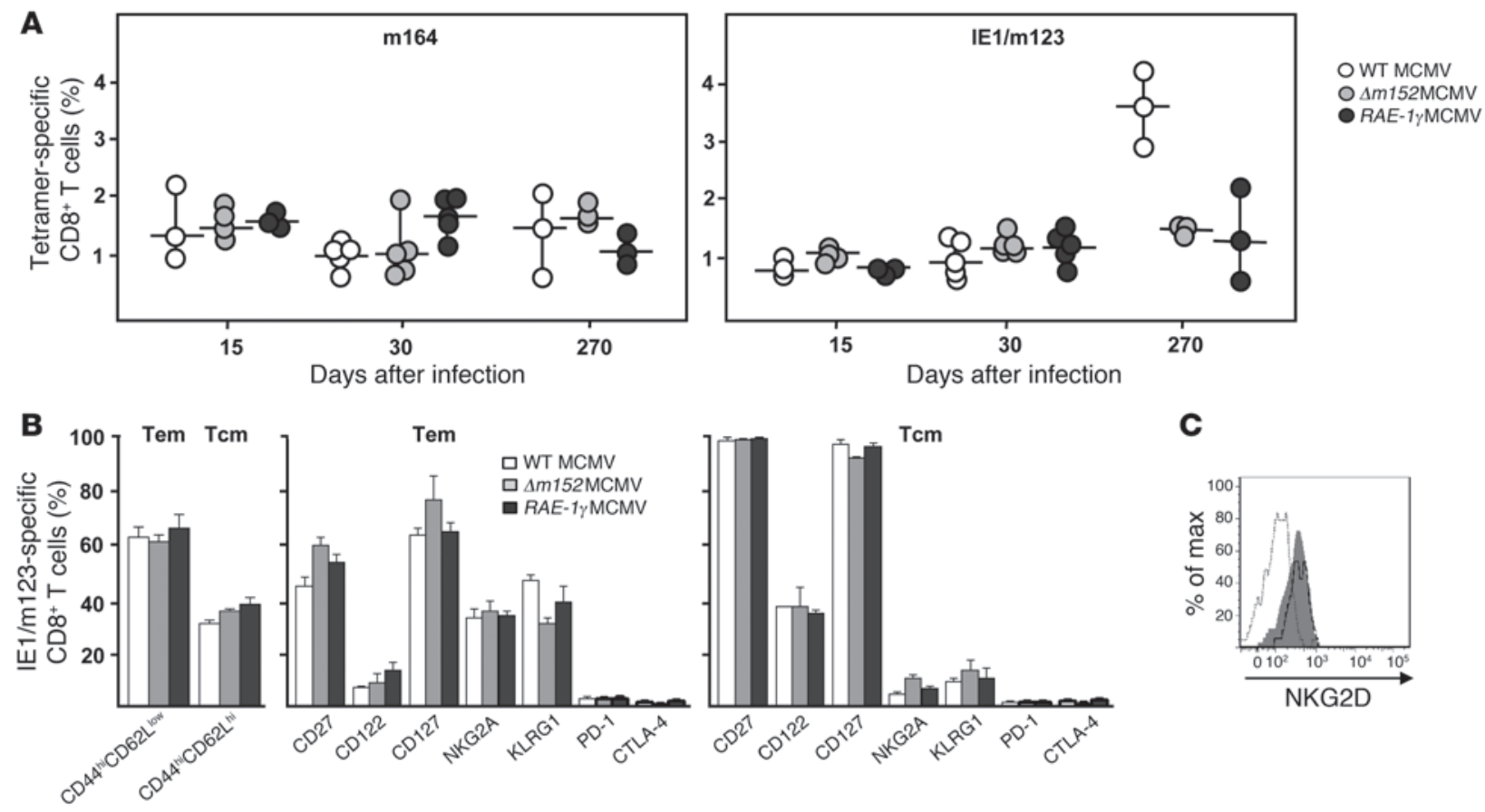

C

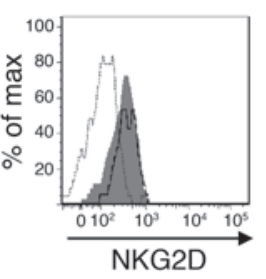

D

WT MCMV

E

WT MCMV

RAE-1 $\gamma$ MCMV
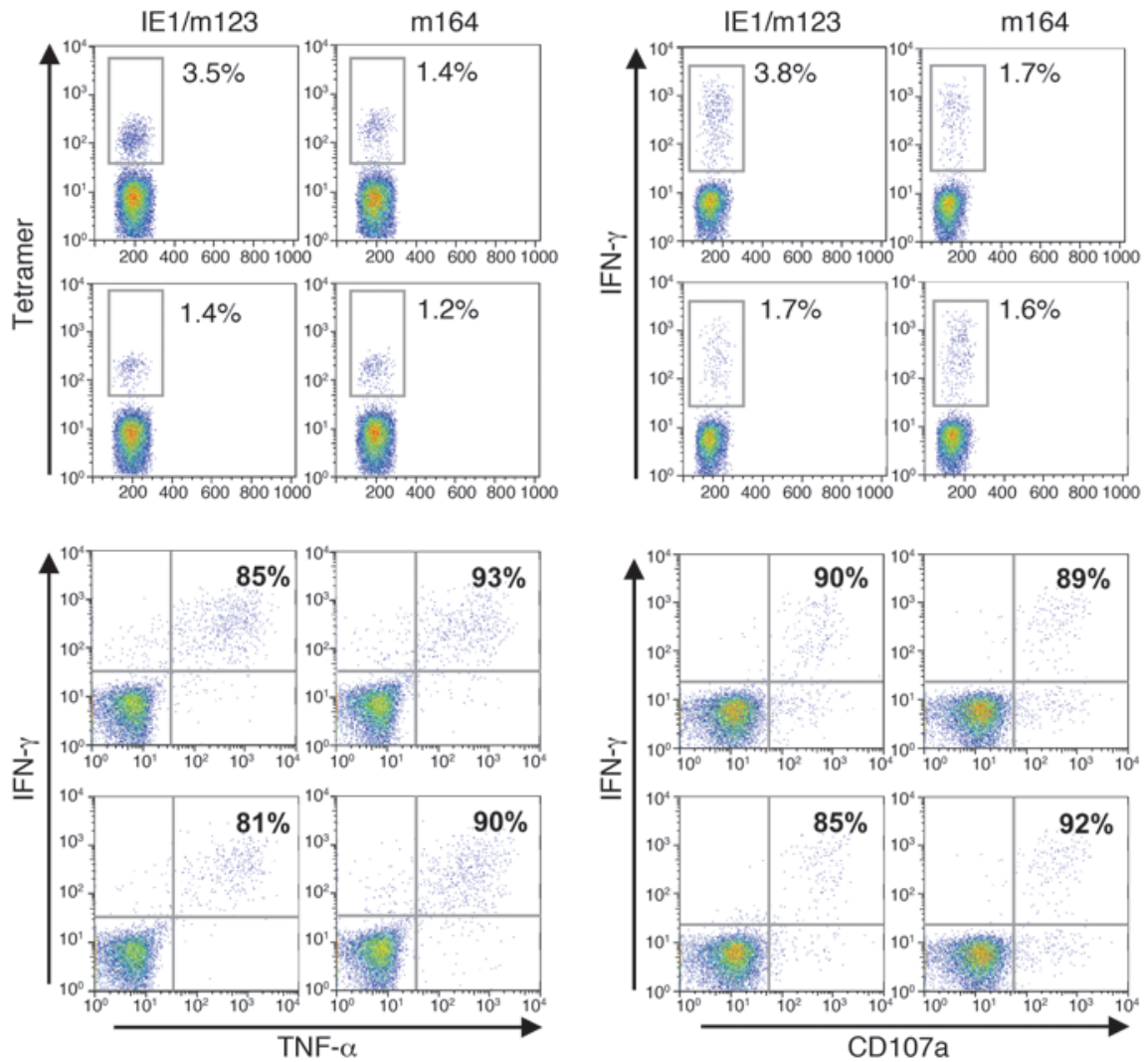


\section{Figure 3}

Comparable kinetics and phenotype of MCMV-specific memory CD8 ${ }^{+} \mathrm{T}$ cells in RAE-1 $\gamma \mathrm{MCMV}-$, WT MCMV-, and $\triangle m 152 \mathrm{MCMV}$-infected mice. (A) BALB/c mice were f.p. injected with $2 \times 10^{5} \mathrm{PFU}$ RAE-1 $\gamma \mathrm{MCMV}$, WT MCMV, or $\triangle m 152 \mathrm{MCMV}$. Splenocytes were isolated at different times after infection and stained with IE $1 / \mathrm{m} 123$ or $\mathrm{m} 164 \mathrm{MHC}$ class I tetramers and anti-CD8 Ab. The percentage of tetramer-specific CD8 ${ }^{+}$ $T$ cells for individual mice (circles) and median values (horizontal bars) are shown. (B) Splenocytes were isolated 9 months p.i. and stained with IE1/m123 MHC class I tetramer, anti-CD8 Ab, and Abs to indicated cell surface molecules. The percentage of IE1/m123-specific CD8 ${ }^{+}$ $T$ cells displaying effector memory (Tem) or central memory (Tcm) phenotype (left) and the percentage of Tem- and Tcm-expressing indicated cell surface molecules are shown (right). Error bars show mean \pm SEM. (C) Representative histogram showing NKG2D staining on IE1/m123specific CD8 ${ }^{+} \mathrm{T}$ cells in spleen 9 months after WT MCMV (filled histogram) or RAE- $1 \gamma \mathrm{MCMV}$ (dotted line) infection. Tetramer-negative CD8+ $T$ cells are indicated by the dashed line. (D) Splenocytes were isolated 9 months $p . i$. and stained with the indicated tetramers or stimulated with the indicated peptides and stained for IFN- $\gamma$ production or (E) costained for IFN- $\gamma$ and TNF- $\alpha$ production. Splenocytes were stimulated as above in the presence of the anti-CD107a Ab and costained for IFN- $\gamma$ production. (D and $\mathbf{E})$ Representative dot plots gated on $\mathrm{CD}^{+} \mathrm{T}$ cells of 3 mice per group are shown. Numbers indicate means. Results from 1 of 2 similar experiments are shown.

WT MCMV replication in salivary glands and lungs were at plateau levels (Figure 2A), and productive infection continued for several months (ref. 43 and data not shown). Similar to results obtained in adult mice, $\triangle m 152 \mathrm{MCMV}$ replication was attenuated compared with WT MCMV but not to the level of RAE-1 $\gamma \mathrm{MCMV}$ attenuation. Furthermore about 3 weeks p.i., $\Delta m 152$ MCMV still replicated to high titers in salivary glands (Supplemental Figure 3). Attenuated $R A E-1 \gamma \mathrm{MCMV}$ replication in neonates led to a lower load of viral DNA in various organs, while prolonged, high-level WT MCMV replication resulted in higher load of viral DNA in organs (Figure $2 \mathrm{~B})$. Collectively, the results indicate that $R A E-1 \gamma \mathrm{MCMV}$ infection in neonates is characterized by attenuated virus replication, shorter duration of the productive infection, and subsequent lower virus DNA load as compared with the WT MCMV.

Efficient priming and maintenance of adaptive immune response after $R A E-1 \gamma M C M V$ infection. To test whether the RAE- $1 \gamma \mathrm{MCMV}$ attenuation impacts on the adaptive antiviral immune response, we injected adult BALB/c mice f.p. with $2 \times 10^{5}$ PFU of RAE- $1 \gamma \mathrm{MCMV}$, WT MCMV, or $\triangle m 152 \mathrm{MCMV}$. The kinetics of the virus-specific T cell response was followed by use of $\mathrm{MHC}$ class I tetramers loaded with MCMV peptides (49). The $\mathrm{CD}^{+} \mathrm{T}$ cell response was dominated by IE $1 / \mathrm{m} 123$-specific and $\mathrm{m} 164$-specific cells, while the response to the 4 other studied epitopes (m04, M83, M84, M45) was low or below the level of detection (Figure $3 \mathrm{~A}$ and data not shown). Following infection with any one of the 3 viruses, the m164-specific $\mathrm{CD}^{+} \mathrm{T}$ cells displayed comparable stable memory kinetics. By contrast, immunoinflation of IE $1 / \mathrm{m} 123$-specific T cells in spleen at 9 months p.i. was less prominent following RAE- $1 \gamma \mathrm{MCMV}$ and $\triangle m 152 \mathrm{MCMV}$ than after WT MCMV infection (50). The kinetics of the antiviral $\mathrm{CD}^{+} \mathrm{T}$ cell response in the blood closely reflected that in spleen (data not shown). The phenotypic and functional properties of virus-specific $\mathrm{CD} 8^{+} \mathrm{T}$ cells were similar following $R A E-1 \gamma \mathrm{MCMV}$, WT MCMV, and $\Delta m 152 \mathrm{MCMV}$ infection (Figure $3 B$ ). Between $60 \%$ and $75 \%$ of IE $1 / \mathrm{m} 123$-specific and $\mathrm{m} 164$-specific $\mathrm{CD}^{+} \mathrm{T}$ cells in spleen and blood retained effector memory pheno- type up to 9 months after infection. It is important to note that the expression of NKG2D, a CD8 ${ }^{+} \mathrm{T}$ cell costimulatory receptor, was essentially identical following both RAE-1 $\gamma \mathrm{MCMV}$ and WT MCMV infection (Figure 3C). Also, the inhibitory receptors PD-1 and CTLA-4, described to be associated with $\mathrm{T}$ cell exhaustion during persistent infections (51), were not upregulated on memory $\mathrm{CD}^{+}$ $T$ cells, and the $T$ cells remained fully functional throughout latent $R A E-1 \gamma \mathrm{MCMV}$ and WT MCMV infection (Figure 3, D and E). At each time point analyzed, the percentage of $\mathrm{CD}^{+} \mathrm{T}$ cells detected by tetramer staining was similar to the percentage of $\mathrm{CD}^{+} \mathrm{T}$ cells secreting IFN- $\gamma$ upon stimulation with a viral antigenic peptide in vitro (Figure $3 \mathrm{D}$ ), and most of the cells simultaneously secreted TNF- $\alpha$, but not IL-2 (Figure 3E and data not shown), and extruded cytotoxic granules (externalized CD107a) (Figure 3E). Interestingly, in $\mathrm{C} 57 \mathrm{BL} / 6$ mice the frequency of MCMV-specific CD8 ${ }^{+}$ $T$ cells at an early time point after $R A E-1 \gamma \mathrm{MCMV}$ infection was even greater compared with WT MCMV (Supplemental Figure 2B).

Similar priming capacity and the frequency of virus-specific $\mathrm{CD}^{+}$ $\mathrm{T}$ cells after infection with RAE- $1 \gamma \mathrm{MCMV}$ or WT MCMV in spite of dramatic differences in the load of infectious virus in their tissues prompted us to test whether this can be explained by a differential effect of RAE-1 $\gamma \mathrm{MCMV}$ and WT MCMV on DCs in vivo. $M C M V$ infection results in a reduction in conventional DCs (cDCs) in $\mathrm{BALB} / \mathrm{c}$ mice that can be prevented by an efficient antiviral NK cell response in the $\mathrm{C} 57 \mathrm{BL} / 6$ strain $(16,52)$. To test how the vaccine virus affects DCs in vivo, we compared DC subsets following $R A E-1 \gamma \mathrm{MCMV}$ and WT MCMV injection in BALB/c mice. While a marked reduction in cDCs occurred at early times after WT MCMV infection, both $\mathrm{CD} 11 \mathrm{~b}^{+}$and $\mathrm{CD} 8 \alpha^{+}$subsets of $\mathrm{cDC}$ s were preserved following RAE-1 $\gamma \mathrm{MCMV}$ infection (Supplemental Figure 4). As reported by others (16), the frequency of cDCs in spleen of infected mice inversely correlated with type I IFN levels in sera of infected mice. At day 2 p.i., the average level of IFN- $\alpha$ in sera was significantly higher after WT MCMV $(5,212 \pm 1,266 \mathrm{pg} / \mathrm{ml})$ as compared with $R A E-1 \gamma \mathrm{MCMV}$ infection $(1,459 \pm 840 \mathrm{pg} / \mathrm{ml})$. Thus, an efficient early control of $R A E-1 \gamma \mathrm{MCMV}$ resulted in preservation of $\mathrm{cDCs}$, possibly by preventing an overwhelming production of type I IFNs, providing optimal conditions for priming of MCMV-specific T cells.

In vivo antiviral effector activity of MCMV-specific memory $\mathrm{CD}^{+} \mathrm{T}$ cells generated following RAE- $1 \gamma \mathrm{MCMV}$ and WT MCMV infection was compared by prophylactic adoptive transfer into immunodepleted MCMV-infected recipient mice. Adoptive transfer of only $10^{3} \mathrm{MCMV}$-specific cells markedly limited virus multiplication, while $10^{4} \mathrm{MCMV}$-specific cells nearly abolished virus replication in spleen. No differences in protective capacity of $\mathrm{CD}^{+}$ $\mathrm{T}$ cells generated following RAE- $1 \gamma \mathrm{MCMV}$ and WT MCMV infection were observed (Figure 4A). Recall response of memory CD8 ${ }^{+}$ $\mathrm{T}$ cells was tested 6 months after the primary infection (Figure 4B and data not shown). The IE1/m123-specific and m164-specific $\mathrm{CD}^{+} \mathrm{T}$ cells in spleen, blood, and tissue rapidly expanded upon challenge infection. Expansion peaked around day 6 after the challenge, resulting in $\mathrm{T}$ cell frequencies several orders of magnitude higher than before the challenge in both RAE-1 $\gamma \mathrm{MCMV}-$ and WT MCMV-infected mice. Thus, although the initial memory $\mathrm{T}$ cell pool was smaller in RAE- $1 \gamma \mathrm{MCMV}$ - than in WT MCMV-infected mice, the size of the resulting $\mathrm{T}$ cell pool after the challenge infection was similar in the two groups of mice. Collectively, these data indicate that despite tight innate immune control, $R A E-1 \gamma \mathrm{MCMV}$ infection elicited a strong, enduring antiviral immune response comparable to that following WT MCMV infection. 


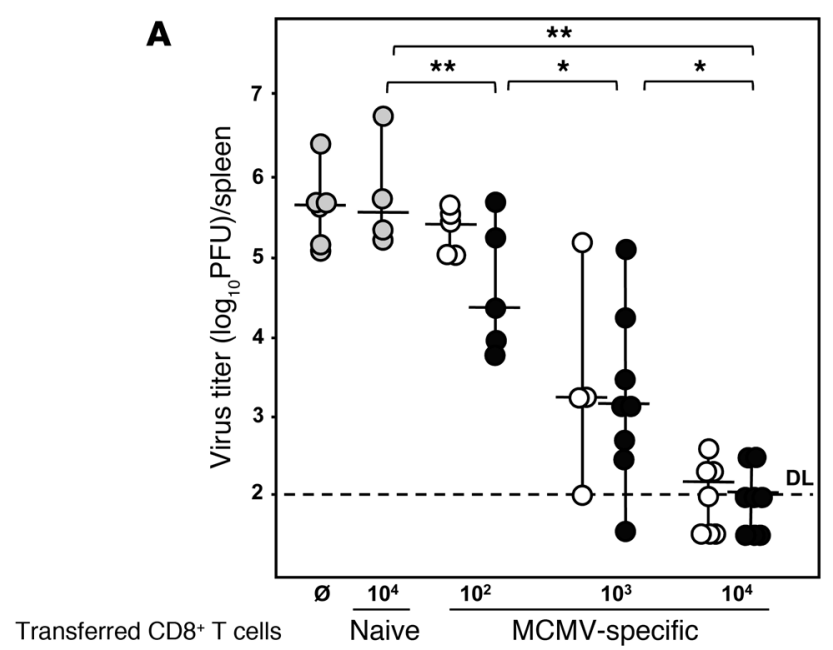

Donors

ONaive

OWT MCMV

$\bullet$ RAE-1yMCMV
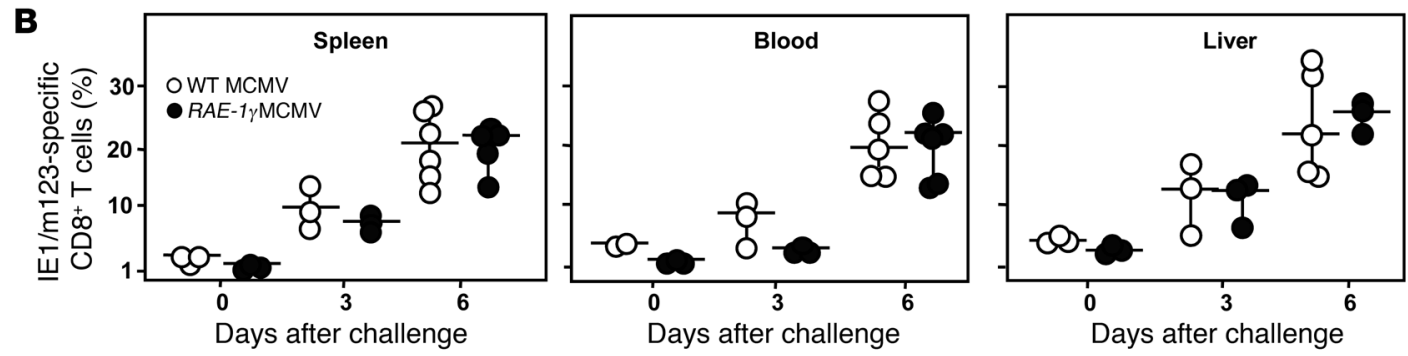

$\mathbf{C}$
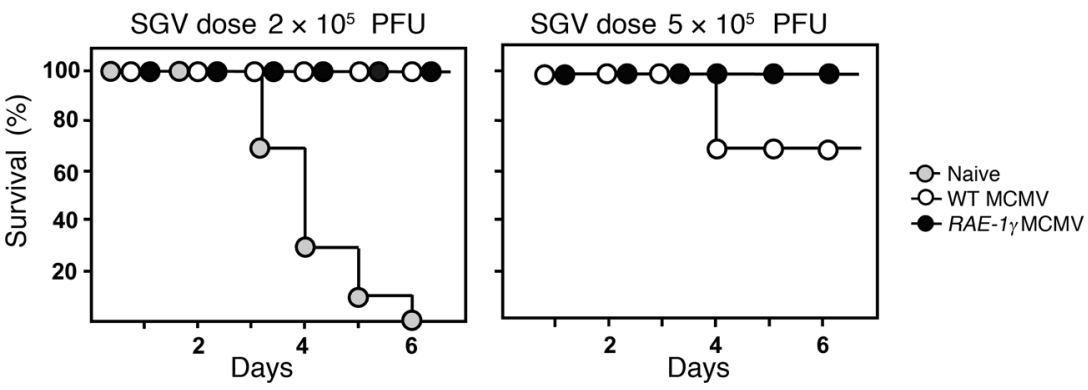

Figure 4

$R A E-1 \gamma \mathrm{MCMV}$ infection induces protective immunity. (A) Donors of memory CD8+ T cells were $\mu \mathrm{MT} / \mu \mathrm{MT}$ B cell-deficient mice either naive or latently infected with $R A E-1 \gamma \mathrm{MCMV}$ or WT MCMV ( $>6$ months p.i.). Splenocytes from 3 donors per group were pooled, and the number of MCMVspecific CD8+ $\mathrm{T}$ cells was assessed by combined staining with IE1/m123, m164, M83, M84, and m04 MHC class I tetramers. $10^{4}$ naive CD8+ T cells or graded numbers of MCMV-specific CD8 ${ }^{+} \mathrm{T}$ cells were i.v. transferred to recipient BALB/c mice immunocompromised by 6 Gy $\gamma$-irradiation. Recipients were f.p. injected with $10^{5}$ PFU WT MCMV 6 hours after the cell transfer. Viral titers in spleen were determined 12 days p.i. by plaque assay. Titers of individual mice (circles) and median values (horizontal bars) are shown. $\varnothing$, no transfer. (B) Mice infected as described in Figure 3 were i.p. challenged with $10^{5}$ PFU of salivary gland-derived MCMV (SGV) 6 months p.i. Lymphocytes were isolated from blood, spleen, and liver at different time points after the challenge and stained with IE1/m123 MHC class I tetramer and anti-CD8 Ab. The percentage of IE1/m123specific CD8 ${ }^{+} \mathrm{T}$ cells for individual mice (circles) and median values (horizontal bars) are shown. (C) Naive mice and mice infected as described in Figure 3 were i.p. challenged with $2 \times 10^{5}$ or $5 \times 10^{5}$ PFU of SGV 6 months p.i. Survival rates were monitored daily. Results from 1 of 2 similar experiment are shown. ${ }^{*} P<0.05,{ }^{* \star} P<0.01$.

RAE-1 $\gamma M C M V$ immunization protects mice from challenge infection. To test whether the immune response induced by the RAE-1 $\gamma \mathrm{MCMV}$ infection is sufficient to protect the host from challenge infection, we injected adult BALB/c mice f.p. with $2 \times 10^{5} \mathrm{PFU}$ of $R A E$ $1 \gamma \mathrm{MCMV}$ or WT MCMV 6 months prior to lethal challenge with salivary gland-derived MCMV (SGV). SGV is more virulent than the cell culture-derived MCMV, and injection of only $10^{5} \mathrm{PFU}$ of SGV results in multiorgan damage and high mortality (53).
While naive mice failed to control the infection and succumbed to a dose of $2 \times 10^{5} \mathrm{SGV}\left(2 \mathrm{LD}_{50}\right)$, all of the mice immunized with $R A E-1 \gamma \mathrm{MCMV}$, similar to the mice previously infected with WT MCMV, survived the challenge (Figure 4C). Notably, mice immunized with $R A E-1 \gamma \mathrm{MCMV}$ resisted challenge infection with $5 \mathrm{LD}_{50}$ of the SGV better than WT MCMV-infected mice, suggesting that expression of NKG2D ligand provides innate immune stimuli that enhance the effectiveness of the adaptive immune response. 
A

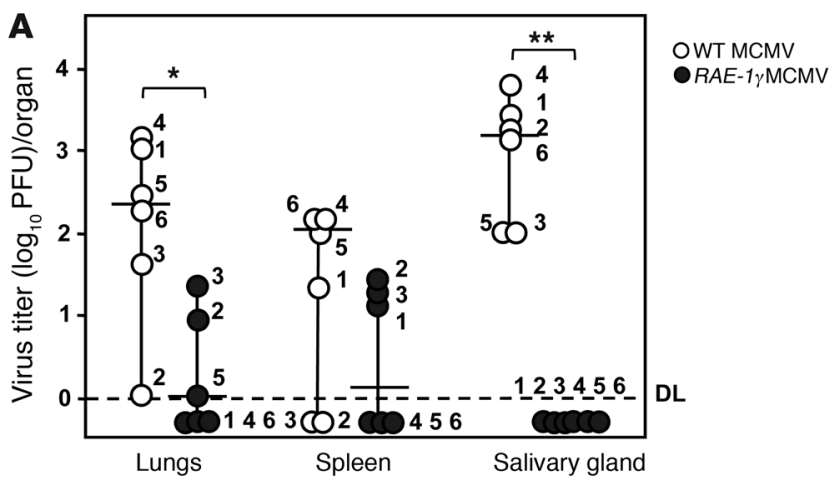

B
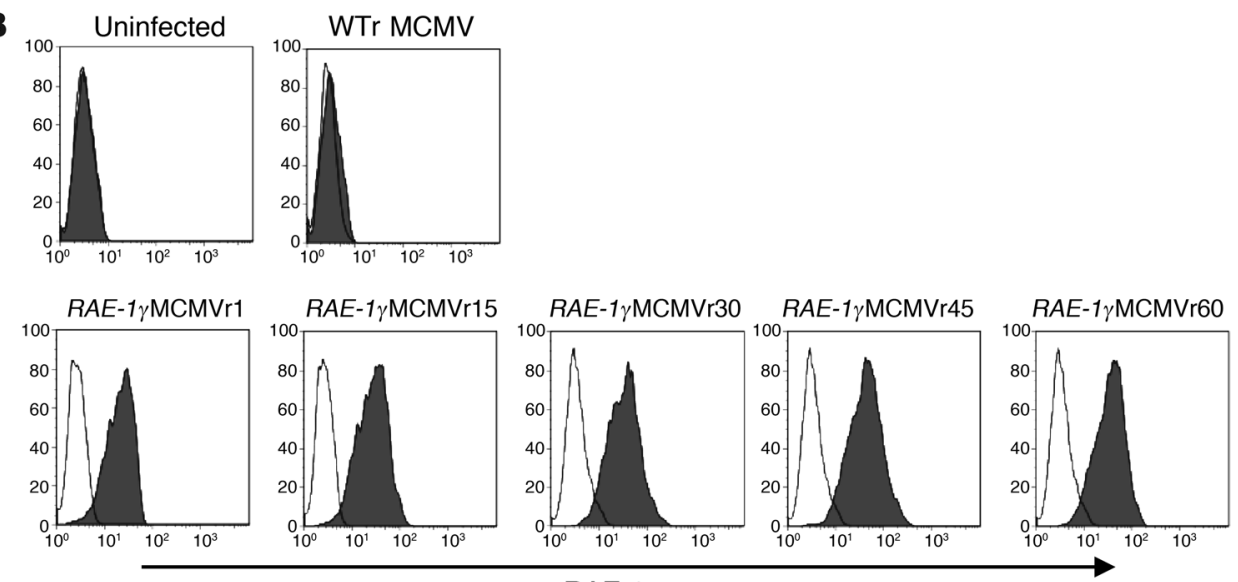

RAE- $1 \gamma$

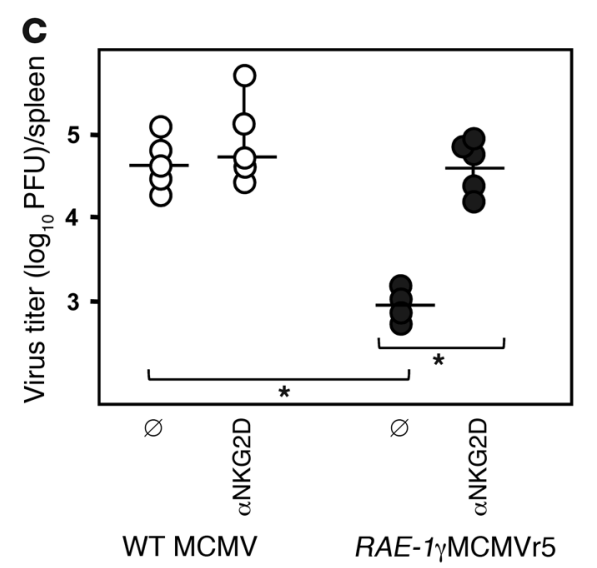

Taken together, the results indicate that immunization with $R A E$ $1 \gamma \mathrm{MCMV}$ induced an immune response that conferred protection against lethal MCMV infection.

Strong attenuation in vivo does not prevent RAE-1 $\gamma M C M V$ from establishing latent infection and reactivating upon immunosuppression. The burden of latent viral DNA in a tissue predetermines the risk of recurrent CMV infection (54). The barely detectable DNA load of RAE-1 $\gamma \mathrm{MCMV}$ during latent infection could limit viral reactivation and subsequent recurrent virus infection. However, kinetics and phenotype of MCMV-specific T cells observed during latent infection were indicative of repeated antigen exposure. Therefore, we investigated the potential of RAE-1 $\gamma \mathrm{MCMV}$ to reactivate from latency by combined depletion of NK cells and T cell subsets in latently infected B cell-deficient mice with a homozygous $\mu$ chain mutation
Figure 5

$R A E-1 \gamma$ remains intact during latent $R A E-1 \gamma \mathrm{MCMV}$ infection. (A) $\mu \mathrm{MT} /$ $\mu \mathrm{MT} B$ cell-deficient mice latently infected with RAE-1 $\gamma \mathrm{MCMV}$ or WT MCMV were depleted of CD4+, $\mathrm{CD}^{+}$, and NK cells by use of Abs. Viral titers were determined by plaque assay 13 days after immunodepletion. Titers of individual mice (circles) and median values (horizontal bars) are shown. Numbers indicate individual mice. (B) A total of 73 recurrent, plaque-purified viruses (termed RAE-1 $\gamma$ MCMVr1 to $R A E-1 \gamma \mathrm{MCMV}$ r73) and recurrent WT MCMV (WTr MCMV) were isolated from organ homogenates of B cell-deficient $\mu \mathrm{MT} / \mu \mathrm{MT}$ mice with recurrent RAE-1 $\gamma \mathrm{MCMV}$ infection. SVEC4-10 cells were infected with the indicated recurrent, plaque-purified RAE-1 $\gamma \mathrm{MCMV}$ viruses and analyzed for surface RAE- $1 \gamma$ expression by FACS as described in Figure 1B. (C) Untreated BALB/c mice or $B A L B / c$ mice treated with blocking anti-NKG2D Ab were i.v. injected with $10^{5}$ PFU WT MCMV or recurrent, plaque-purified RAE- $1 \gamma \mathrm{MCMV}$ (clone RAE-1 $\gamma \mathrm{MCMV}$ r5). Viral titers were determined in spleen 3 days p.i. by plaque assay. Titers of individual mice (circles) and median values (horizontal bars) from a representative of two independent experiments are shown. ${ }^{*} P<0.05$, ${ }^{* *} P<0.01$. 
A

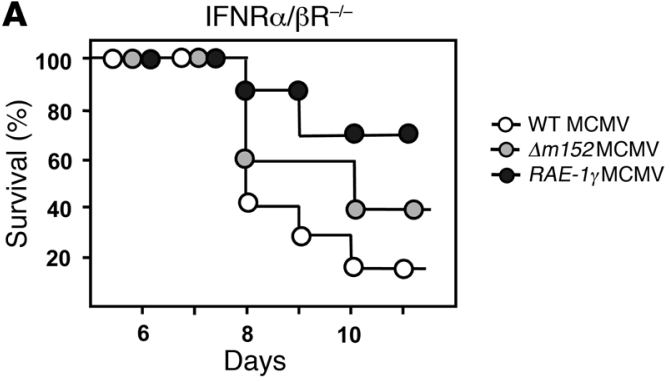

B

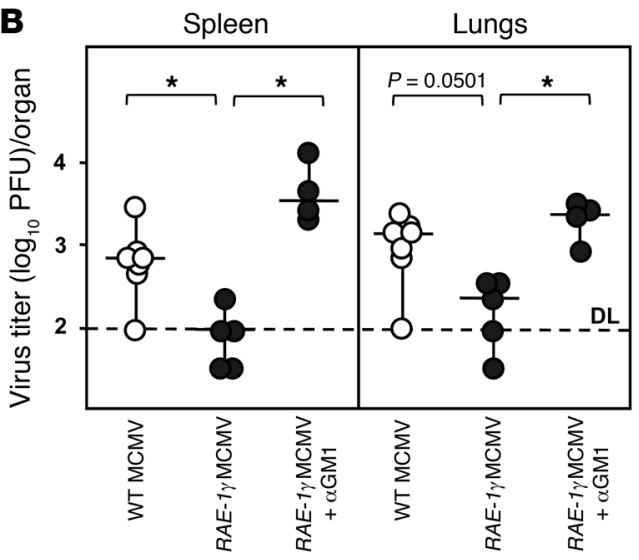

virus mutants that escape from the immune control, even in herpes viruses with highly accurate mechanisms of genome replication $(55,56)$. To address whether a strong immune response can drive emergence of $R A E-1 \gamma \mathrm{MCMV}$ mutants that escape from NKG2Dmediated immunosurveillance, we prepared plaque-purified viruses from spleen and lung homogenates of B cell-deficient $\mu \mathrm{MT} / \mu \mathrm{MT}$ mice with recurrent $R A E-1 \gamma \mathrm{MCMV}$ infection (see above). A total of 73 plaque-purified isolates (termed $R A E-1 \gamma \mathrm{MCMVr} 1$ to $R A E$ $1 \gamma \mathrm{MCMVr} 73$ ) were tested for the expression of RAE- $1 \gamma$, and some of them were tested for sensitivity to the NKG2D-mediated immune control in vivo. Infection of SVEC4-10 cells with plaque-purified isolates resulted in cell surface expression of RAE- $1 \gamma$ as detected by FACS analysis (Figure 5B), and infection of BALB/c mice with a $R A E$ $1 \gamma \mathrm{MCMVr}$ isolate (RAE- $1 \gamma \mathrm{MCMVr} 5)$ resulted in NKG2D-dependent attenuation of virus replication similar to the attenuation of parental RAE-1 $\gamma \mathrm{MCMV}$ (Figure 5C). Finally, PCR amplification of RAE- $1 \gamma$ was performed, and sequence analysis of PCR products did not reveal sequence variation in any of $30 R A E-1 \gamma \mathrm{MCMVr}$ isolates tested (data not shown). These data indicate that despite strong selective pressure imposed by NKG2D-dependent immune control mechanisms, the $R A E-1 \gamma$ transgene encoded by $R A E-1 \gamma \mathrm{MCMV}$ remained intact.

Control of RAE-1 $\gamma M C M V$ in mice lacking the receptor for type IIFNs and after hematoablative irradiation. Type I IFNs play an important role in limiting MCMV replication during the early stage of infection. Consequently, mice lacking the receptor for type I IFNs (IFN- $\alpha$ / $\beta \mathrm{R}^{-/-}$mice) are 1,000-fold more susceptible to MCMV infection than the parental mouse strain (57). To test whether RAE-1 $\gamma \mathrm{MCMV}$ is efficiently controlled even in the severely immunodeficient host, we injected IFN- $\alpha / \beta \mathrm{R}^{-/-}$mice i.p. with $R A E-1 \gamma \mathrm{MCMV}$, WT MCMV, or $\Delta m 152 \mathrm{MCMV}$. While most of the WT MCMV- and $\Delta m 152$ MCMV-infected mice succumbed to the infection $(85 \%$ and $60 \%$, respectively), the mortality rate of the RAE-1 $\gamma \mathrm{MCMV}$-infected animals was significantly lower (30\%) (Figure 6A).

\section{Figure 6}

$R A E-1 \gamma \mathrm{MCMV}$ is attenuated in immunocompromised host. (A) IFN- $\alpha /$ $\beta \mathrm{R}^{-1-}$ mice were i.p. injected with $2 \times 10^{5} \mathrm{PFU}$ of $R A E-1 \gamma \mathrm{MCMV}$, WT MCMV, or $\triangle m 152 \mathrm{MCMV}$, and survival rates were monitored daily. Combined results from 2 similar experiments are shown. (B) BALB/C mice were subjected to 6 Gy total-body $\gamma$-irradiation 6 hours prior to f.p. injection with $10^{5} \mathrm{PFU}$ of $R A E-1 \gamma \mathrm{MCMV}$ or WT MCMV. Some groups of mice were depleted of NK cells by anti-asialoGM1 ( $\alpha \mathrm{GM} 1)$ Ab. Viral titers were determined 7 days p.i. by plaque assay. Titers of individual mice (circles) and median values (horizontal bars) are shown. ${ }^{*} P<0.05$.

NK cells are more resistant to irradiation than other lymphoid cells $(58,59)$, and RAE- $1 \gamma \mathrm{MCMV}$ is extremely sensitive to the NK cell control. We assessed whether residual NK cells, after hematoablative treatment, are sufficient to control RAE-1 $\gamma \mathrm{MCMV}$ infection. BALB/c mice were hematoablated using a sublethal dose ( $6 \mathrm{~Gy}$ ) of total body $\gamma$-irradiation 6 hours prior to f.p. injection with $10^{5} \mathrm{PFU}$ of RAE- $1 \gamma \mathrm{MCMV}$ or WT MCMV, and viral titers were compared on day 7 p.i. $R A E-1 \gamma \mathrm{MCMV}$ infection in hematoablated mice resulted in significantly lower viral titers as compared with WT MCMV infection, suggesting that residual NK cells are sufficient to restrain $R A E-1 \gamma \mathrm{MCMV}$ infection (Figure 6B). Together, these data indicate that infection with the $R A E-1 \gamma \mathrm{MCMV}$ presents a low risk for disease, even in severely immunodeficient hosts.

Maternal RAE-1 $\gamma M C M V$ immunization protects neonatal mice from $M C M V$ infection. Maternal preconception immunity to CMV provides substantial protection against congenital infection (60-62). The presence of maternal antiviral Abs is associated with a decreased incidence of intrauterine transmission and better neurological outcomes in the setting of congenital infection. The role of $\mathrm{Abs}$ in the prevention of congenital infection has also been emphasized in the guinea pig CMV model (63). Since the mouse hemoplacental barrier does not support MCMV transfer, we established a model of i.p. neonatal MCMV infection whose pathogenesis closely resembles congenital HCMV infection (64). To test whether the maternal $\mathrm{Ab}$ response induced by the RAE- $1 \gamma \mathrm{MCMV}$ immunization can protect neonatal mice from MCMV infection, we injected female BALB/c mice with RAE-1 $\gamma \mathrm{MCMV}$ or WT MCMV or mock infected them 2 weeks before mating. A number of neonates were sacrificed on the day of birth and tested for the presence of antiviral Abs in serum, while the others were i.p. injected with 500 PFU WT MCMV and tested for replicating virus in the tissue. No antiviral Abs were detected in the serum of neonates of naive females. By contrast, antiviral Abs were detected in serum of RAE$1 \gamma \mathrm{MCMV}$ - and WT MCMV-immunized females and in serum of their neonates, confirming passive placental transfer of antiviral Abs (Figure 7A). Whereas MCMV infection in infected neonates of naive females resulted in disseminated virus replication, no replicating virus was detected in various tissues at day 9 after the infection in neonates of RAE- $1 \gamma \mathrm{MCMV}$-immunized females or in neonates of WT MCMV-immunized females (Figure 7B). Thus, immunization with recombinant $R A E-1 \gamma \mathrm{MCMV}$ induced a mater$\mathrm{nal} \mathrm{Ab}$ response that, upon placental transfer, limited virus dissemination and protected neonatal mice from MCMV infection.

\section{Discussion}

Despite efforts, no effective HCMV vaccine is currently available. Several features of HCMV make vaccine development extremely difficult. First, a large number of viral immunoevasion proteins subvert the host's immune responses at virtually every step. Sec- 
A

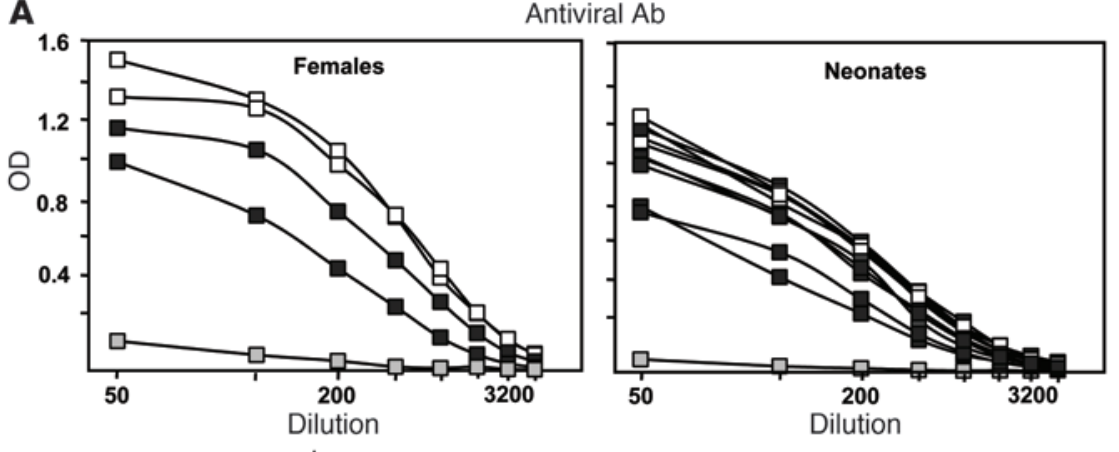

\section{Figure 7}

Maternal immunization with $R A E-1 \gamma \mathrm{MCMV}$ protects offspring from MCMV disease. (A) Female $\mathrm{BALB} / \mathrm{c}$ mice were i.v. injected with $2 \times 10^{5} \mathrm{PFU}$ of $R A E-1 \gamma \mathrm{MCMV}$ or WT MCMV or mock injected 2 weeks before mating. Antiviral Ab titers in their serum and in serum of their neonates were determined by ELISA 6 hours postpartum. (B) A group of the neonates was i.p. injected with 500 PFU WT MCMV 6 hours postpartum, and viral titers were determined in various organs 9 days p.i. by plaque assay. Titers of individual mice (circles) and median values (horizontal bars) are shown.

the design of rational mutants as CMV vaccine candidates $(74,75)$. The vaccination potential of CMV mutants lacking nonessential viral genes has already been proven $(33,34)$. Also, spread-deficient MCMV lacking the essential gene M94 induced a virus-specific immune response and proved to be safe in an immunodeficient host (31). The approach of the present study was to generate an experimental vaccine expressing NKG2D ligand, which is therefore attenuated due to strong immune control and, at the same time, resistant to viral immunoevasion of this signaling pathway. The recombinant virus expressing the NKG2D ligand RAE- $1 \gamma$ was severely attenuated in vivo in an NKG2D-dependent manner, not only in the immunocompetent host but also in immunologically immature neonates and mice immunodepleted by sublethal $\gamma$-irradiation or in mice lacking the receptor for type I IFNs.

The definition of herpes virus latency (76) implies that the viral genome is maintained and can reactivate to productive infection.

ond, immunity from naturally acquired infection is not completely protective against superinfection or CMV transmission from mother to fetus $(60,62,65)$. Third, persistence of virus in the state of latency with the possibility of reactivation and disease in immunocompromised patients represents a safety concern when a replicating CMV is considered for use as vaccine candidate. Still, a live, attenuated vaccine approach has several characteristics that render it attractive. Unlike subunit vaccines, which induce cellular or humoral immune response to selected antigens only, live vaccines induce a much broader immunity that may mimic protection acquired following natural infection (31, 33, 66-69). Cellular immunity against CMV follows unique kinetics characterized by maintenance or even expansion of the virus-specific $\mathrm{CD}^{+} \mathrm{T}$ cell response over time $(70,71)$. In addition, recombinant CMVs that expressed heterologous simian immunodeficiency virus, lymphocytic choriomeningitis virus, and influenza virus peptides have been shown to induce protective immunity against the respective viruses $(72,73)$. Therefore, live, attenuated CMVs are attractive candidates for a CMV vaccine or a CMV-based vaccine vector provided that their pathogenicity is significantly attenuated but their immunogenicity is unaffected.

A better understanding of viral immunobiology and the introduction of BAC technology have made the CMV genome accessible to
The data from the MCMV model have shown that the conditions of the primary infection predetermine the risk of reactivation by modulating the latent viral load (43). Despite accelerated viral clearance during primary infection and barely detectable viral DNA load, $R A E-1 \gamma \mathrm{MCMV}$ was able to reactivate upon immunodepletion. Still, the incidence of recurrence and viral titers were lower in RAE- $1 \gamma \mathrm{MCMV}$ - than in WT MCMV-infected mice, most probably as a consequence of a lower load of latent viral genome. Under selective pressure imposed by the immune control mechanism, apathogenic vaccine strains may become pathogenic due to the emergence of escape mutants no longer sensitive to immunosurveillance $(56,77)$. However, sequencing of plaque-purified isolates from mice with recurrent $R A E-1 \gamma \mathrm{MCMV}$ infection did not reveal any $R A E-1 \gamma$ mutations, and the susceptibility of the isolates to the NKG2D-mediated immune control was comparable to that of the parental RAE-1 $\gamma \mathrm{MCMV}$. Efficient NK cell and T cell response may have suppressed virus replication to the extent that emergence of virus escape mutants was restricted. We speculate that such a low level of $R A E-1 \gamma \mathrm{MCMV}$ genome is sufficient to elicit nonproductive reactivations and boost cells of the immune system. Still, due to low-level recurrence and intact $R A E-1 \gamma$ transgene, the virus would be efficiently controlled even in the severely immunocompromised host provided that some residual NK cell response remains. 
The salivary glands are the privileged organ for CMV replication in that productive infection continues long after innate and adaptive immune responses have cleared MCMV from other organs (43, 44). RAE-1 $\gamma \mathrm{MCMV}$ infection of mice led to the emergence of new, extremely favorable biological characteristics, including the lack of detectable infectious virus in salivary glands during primary or recurrent infection in $\mathrm{BALB} / \mathrm{c}$ mice. We propose that attenuated $R A E-1 \gamma \mathrm{MCMV}$ multiplication and dissemination during primary infection restricted salivary gland colonization, prevented productive infection, and prohibited $R A E-1 \gamma \mathrm{MCMV}$ reactivation in salivary gland upon immunosuppression. It is thus likely that salivary shedding of RAE- $1 \gamma \mathrm{MCMV}$ is absent and horizontal transmission via saliva could be expected to be eliminated or significantly reduced.

It is generally accepted that the innate immune system has a key role in determining the strength and quality of the adaptive immune response. However, whether a strong innate immune response is beneficial or, alternatively, detrimental for priming and maintenance of efficient adaptive immunity is a matter of debate. Robbins et al. reported that an efficient NK cell response promotes adaptive immunity, in part by preventing production of high, immunosuppressive levels of IFN- $\alpha / \beta$ and other innate cytokines (16). However, if viral replication is too attenuated, the low antigen supply may limit priming and maintenance of efficient immune response (78). Andrews et al. recently reported that $\mathrm{Ly}_{49 \mathrm{H}^{+}} \mathrm{NK}$ cells negatively regulate $\mathrm{T}$ cell response following MCMV infection by limiting exposure of $\mathrm{T}$ cells to infected APCs (52). According to these authors, an efficient NK cell response negatively impacts the ability of specific immune responses to limit persistent viral replication. However, our results do not support the notion that strong NK cell response in general would compromise specific immune response against herpesviruses. We report that efficient early control of virus guided by NKG2D-dependent mechanisms does not affect generation, strength, and longevity of specific, protective immune response. Although it is currently difficult to explain the differences between the above-mentioned and our findings, it should be pointed out that unlike Ly49H, NKG2D receptor also serves as a costimulatory molecule on $\mathrm{CD}^{+} \mathrm{T}$ cells, which may additionally influence the quality of the $\mathrm{CD}^{+} \mathrm{T}$ cell response toward RAE-1 $\gamma \mathrm{MCMV}$. Although NK cell activation via Ly49H or NKG2D can overcome the viral evasion of NK cells, it is worth mentioning that virus expressing RAE- $1 \gamma$ is attenuated even in C57BL/ 6 mice, suggesting that effector functions mediated through these two receptors do not completely overlap. Furthermore, unlike the MCMV gene $m 157$, the RAE- $1 \gamma$ expressed in the context of virus genome was not subject to escape by mutation or deletion due to the strong selective pressure. Permanent and strong susceptibility of $R A E-1 \gamma \mathrm{MCMV}$ to the immune control may explain its inability to reach salivary glands of immunocompetent adult mice. Alternatively, the NKG2D-dependent immune control in salivary gland may be more efficient as compared with other tissues.

Virus-specific $\mathrm{CD}^{+} \mathrm{T}$ cells generated by $R A E-1 \gamma \mathrm{MCMV}$ infection have predominantly an effector memory phenotype and provide long-term protective immunity and thus were similar to those generated following WT MCMV infection. One reasonable explanation for the unique pattern of the $\mathrm{CD}^{+} \mathrm{T}$ cell phenotype and kinetics in MCMV-infected mice is repetitive exposure to antigen during low-level transcription of viral genes during latency leading to endogenous boosting. The frequency of abortive MCMV reactivation during latency depends on the amount of latent viral genome (54), which may account for the restricted immunoinfla- tion of MCMV-specific CD8 ${ }^{+} \mathrm{T}$ cells after low-dose $\left(2 \times 10^{5} \mathrm{PFU}\right)$ intraplantar infection and the stable memory kinetics of IE1/ $\mathrm{m} 123$ - and $\mathrm{m} 164-$ specific $\mathrm{CD} 8^{+} \mathrm{T}$ cells following RAE- $1 \gamma \mathrm{MCMV}$ infection. Despite of the predominance of the effector memory phenotype indicative of repeated antigen encounter, virus-specific $\mathrm{CD}^{+} \mathrm{T}$ cells did not show upregulation of inhibitory receptors such as PD-1 or CTLA-4, nor any signs of functional exhaustion (51). In addition, expression of RAE- $1 \gamma$ by MCMV did not affect NKG2D expression by CD8 ${ }^{+} \mathrm{T}$ cells, which remained similar during $R A E-1 \gamma \mathrm{MCMV}$ and WT MCMV infection.

The RAE- $1 \gamma \mathrm{MCMV}$ was constructed by insertion of the RAE- $1 \gamma$ ORF into the $\Delta m 152 \mathrm{MCMV}$ genome. The product of the $m 152$ gene, in addition to downregulating RAE- $1 \gamma$, targets MHC class I presentation and impairs $\mathrm{CD}^{+} \mathrm{T}$ cells recognition of infected cells $(41,79,80)$. However, previous work has shown that the presence or absence of MHC I immune evasion proteins has little impact on the size and specificity of the antiviral $\mathrm{CD}^{+} \mathrm{T}$ cell response over the course of infection (81). The latter finding is explained by the fact that the majority of $\mathrm{MCMV}$-specific $\mathrm{CD}^{+} \mathrm{T}$ cells are primed not by infected professional APCs directly, but rather by antigen cross-presentation (69).

An important goal of CMV vaccine development is to develop a candidate vaccine that provides protection from disease associated with intrauterine CMV infection (10). Although mice have not been utilized as a model for congenital infection because of the restrictions of fetal infection secondary to the anatomy of the mouse placenta, newborn animals have been used to model the CNS disease and sequelae associated with congenital CMV infection (64). Importantly, the newborn mouse is developmentally similar to the late-second-trimester human fetus, and infection delivered by an i.p. inoculation can lead to CNS infection and disease whose pathogenesis closely resembles that which is thought to occur in the infected human fetus. Furthermore, passively acquired antiviral Abs are thought to modulate infection and disease in infected newborn mice in a fashion similar to transplacentally acquired maternal $\mathrm{Abs}$ in human fetuses infected in utero (24). Infected neonates born to RAE-1 $\gamma \mathrm{MCMV}$-vaccinated mothers had diminished viral titers in all organs and no virus-induced organ damage, including CNS sequelae. Thus, our data provide evidence of protective immunity against neonatal infection and disease induced by maternal $R A E-1 \gamma \mathrm{MCMV}$ vaccination that is comparable to that induced by maternal WT MCMV infection. Together, these findings demonstrate the efficacy of an attenuated MCMV vaccine expressing the NKG2D ligand to generate a robust and persistent protective immune response integrating all components of the immune system.

Multiple approaches have been proposed for attenuation of CMVs; however, since the biological target of attenuation, i.e., prevention of infection, disease, or transmission, is experimentally ill-defined, optimal attenuation of this virus remains speculative. We hypothesize that optimal attenuation should result in a virus that can replicate sufficiently to induce adaptive immunity, thereby establishing immunological memory and an attenuated level of persistence at the same time. Here we demonstrated that CMV engineered to express ligand for NK cell-activating receptor NKG2D led to not only strong attenuation in immunocompetent host but also additional results beneficial for attenuated vaccine candidates, including (a) optimal priming and enduring protective $\mathrm{T}$ and $\mathrm{B}$ cell responses; (b) attenuated phenotype even in immunologically immature or immunodeficient hosts; (c) preservation of 
transgene in spite of the strong selective pressure imposed by NK cells; (d) minimal risk of recurrence, and (e) altered virus distribution, as illustrated by the failure of such virus to colonize salivary gland. The latter property would provide a more favorable safety profile for a replicating vaccine by limiting the transmission within the population and possibly to offspring. Moreover, upon maternal vaccination with MCMV expressing NKG2D ligand, transplacental transfer of antiviral Abs protected neonatal mice from CMV disease. With respect to the use of live, attenuated viruses such as CMVs, one should also point out the large potential of these viruses to serve as live vaccine vectors (73). We believe that approaches such as the one described in this article will be feasible in the near future.

\section{Methods}

Cells and viruses. Mouse embryonic fibroblasts (MEFs) and SVEC4-10 (ATCC CRL-2181), NIH 3T3 (ATCC CRL-1658), and B12 fibroblasts (82) were grown as described previously (83). A BAC-derived MCMV, MW97.01, has previously been shown to be biologically equivalent to the MCMV Smith strain (VR-194 [reaccessioned as VR-1399]; ATCC) and is here referred as WT MCMV. The recombinant strain $\triangle m 152 \mathrm{MCMV}$ was generated as described previously $(84,85)$. Viruses were propagated on MEFs and concentrated by sucrose gradient ultracentrifugation (83). The SGV MCMV was used as a third passage and prepared as described previously (83).

Construction of recombinant plasmids and recombinant viruses. To generate the $R A E-1 \gamma \mathrm{MCMV}$ mutant, an ORF encoding FLAG-tagged RAE- $1 \gamma$ was first cloned into pGL3 (Invitrogen) together with a kanamycin resistance gene (kanR), which was inserted further downstream. Then, the RAE-1 $\gamma$ expression cassette plus kanR were PCR amplified using the primers 5'-GCACCCGACGATCTGACATTGTCCAGTGTGCCGGTCGCACGAACATCCCTAGTTATTAATAGTAATC-3' and 5'-TGTCACCGCTCCACGTTTCACCGTCGGTCTCCCGATCGCTAGCCTGTACACAGGAACACTTAACGGCTGA-3', which contained 50 nucleotides at their $5^{\prime}$ ends homologous to the intended integration site in the BAC-cloned MCMV genome. The PCR fragment was integrated into the BAC by red $\alpha,-\beta,-\gamma$-mediated recombination as described previously (86), thereby replacing the $152 \mathrm{ORF}$. The kanR cassette was subsequently excised with FLP recombinase $(87,88)$. The resulting MCMV BAC was characterized by restriction analysis, and the mutant was reconstituted by transfection of the BAC DNA into MEFs.

Animals, infection, and lymphocyte subset depletion. BALB/c ( $\left.\mathrm{H}-2^{\mathrm{d}}\right), \mathrm{C} 57 \mathrm{BL} / 6$ $\left(\mathrm{H}-2^{\mathrm{b}}\right.$ ), IFN type I receptor ${ }^{-/-}$mice on a 129 background (IFN- $\alpha / \beta \mathrm{R}^{-/-}$), and $\mathrm{BALB} / \mathrm{c}\left(\mathrm{H}-2^{\mathrm{d}}\right) \mu \mathrm{MT} / \mu \mathrm{MT}$ mice (89) were bred under specific pathogen-free conditions at the Central Animal Facility of the Faculty of Medicine, University of Rijeka. Animal handling, experimental procedures, and administration of anesthesia were performed in accordance with the guidelines contained in the Council for International Organizations of Medical Sciences International Guiding Principles for Biomedical Research Involving Animals. The Ethics Committee of the University of Rijeka approved all animal experiments described within this report. Unless otherwise indicated, mice were injected f.p. with $2 \times 10^{5} \mathrm{PFU}$ of tissue culture-derived MCMV at the age of 6-8 weeks. Neonatal mice were i.p injected with 500 PFU MCMV 6 hours postpartum. In vivo blocking of NKG2D and depletion of $\mathrm{CD}^{+}$ $\mathrm{T}$ cells, $\mathrm{CD}^{+} \mathrm{T}$ cells, and NK cells were performed by i.p. injection of $\mathrm{mAb}$ (rat anti-mouse) to NKG2D (R\&D Systems), CD4 (YTS 191.1), CD8 (YTS 169.4), and anti-asialoGM1 serum (Wako Chemicals), respectively.

Viral titers and real-time PCR. Viral titers were determined using a standard plaque assay (90). The detection limit of the assay was extended to 1 PFU per organ homogenate as described previously (19). Genomic DNA was extracted from mouse tissues $(10 \mathrm{mg})$ or blood $(300 \mu \mathrm{l})$ using Wizard Genomic DNA Purification Kit (Promega), according to the instruc- tion manual, and dissolved in $100 \mu \mathrm{l}$ of DNA Rehydration Solution. Viral genome was quantified by real-time PCR using the LightCycler system (Roche) and LightCycler Fast Start DNA MasterPlus SYBR Green I and analyzed by LightCycler data analysis software version 3.3.40. Primers ie4fwd (5'-TGACTTAAACTCCCCAGGCAA-3') and ie4rev (5'-TAGGTGAGGCCATAGTGGCAG-3'), nucleotide positions 6692-6672 and 6592-6612, respectively (GenBank L06816), were chosen to amplify a segment of exon 4 of the ie1 gene. A cellular gene was detected with primers glralfwd (5'-TGCCTGTTCTTTGCAGTCTGT-3') and glra1rev (5'-AGTCGAGTGAAGGGTAACGAGC-3'), nucleotide positions 312-332 and 403-382, respectively (GenBank X75832). Specificity of PCR products was determined by melting curve analysis. Serial dilutions of pGEM-T Easy Vector (Promega) expressing partial MCMV ie1 gene and of DNA extracted from MEFs were used as standards to determine the MCMV genome copy numbers and the number of cells, respectively. Tissue DNA samples from uninfected mice and multiple samples without template served as negative controls. The PCR amplification efficiencies $(E)$ for the ie1 and glra1 standard curves as well as for both genes in a titration of sample DNA were calculated according to the formula $E=10^{-1 / \text { slope }}$ (technical note no. LC11/2000; Roche) and differed by $\Delta E<0.05$ in the reported experiments. Likewise, for each of the two genes tested, amplification efficacies differed by $\Delta E<0.05$ between a titration of sample DNA and the respective standard curve. To determine sensitivity of quantitative PCR (qPCR) detection of MCMV, genomic DNA samples were spiked with serial dilutions of target plasmid PGEM-T Easy Vector containing ie1 genomic sequence as template in the PCR as previously described (91). The detection limit was found to be 6 copies of MCMV per $10^{6}$ cells.

Adoptive transfer of $M C M V$-specific $C D 8^{+} T$ cells. Adoptive transfer experiments were performed as described previously (92). In short, donors of $\mathrm{CD}^{+} \mathrm{T}$ cells were naive or latently infected $\mu \mathrm{MT} / \mu \mathrm{MT}$ (B cell-deficient) mice, MCMV infected 6 months before the adoptive transfer. Splenocytes from 3 donors per group were pooled, and the number of MCMV-specific $\mathrm{CD}^{+} \mathrm{T}$ cells was assessed by combined staining with IE1/m123, m164, M83, M84, and m04 MHC class I tetramers. Unfractionated splenocytes containing $10^{5}$ naive $\mathrm{CD}^{+} \mathrm{T}$ cells or graded numbers of MCMV-specific CD8 ${ }^{+} \mathrm{T}$ cells were i.v. transferred to recipient $\mathrm{BALB} / \mathrm{c}$ mice immunocompromised with a single dose of 6 Gy $\gamma$-irradiation 12 hours prior to adoptive transfer. Recipients were f.p. injected with $10^{5}$ PFU WT MCMV 6 hours after the adoptive transfer. Viral titers in the spleen were determined 12 days p.i. by plaque assay.

Flow cytometry and intracellular staining. Custom MCMV-specific $\mathrm{H}-2^{\mathrm{d}}$ and $\mathrm{H}-2^{\mathrm{b}}$ class I-restricted antigenic peptide synthesis to a purity of greater than $80 \%$ was performed by Jerini Peptide Technologies. Tetramers were synthesized by the NIH Tetramer Core Facility. Various fluorescently conjugated Abs were used: CD8 $\alpha$ (clone 53-6.7), CD27 (LG.7F9), CD62L (MEL-14), CD122 (5H4), CD127 (A7R34), KLRG-1 (2F1), NKG2A/C/E (20D5), NKG2D (M1-6), CTLA-4 (UC10-4B9), PD-1 (J43), IL-2 (JES6-SH4), IFN- $\gamma$ (XMG1.2), TNF- $\alpha$ (MP6-XT22), CD3 $\beta$ (H57-597), CD11c (N418), NKp46 (29A1.4), PDCA-1 (eBio927), RAE-1 $\gamma$ (CX1), RAE-1 $\alpha \beta \delta \varepsilon$ (clone 199205), MULT-1 (clone 237104), H60 (clone 205326). An in vitro assay to detect cytokine production and degranulation was preformed as previously described (33). In short, splenocytes were resuspended in complete RPMI 1640 supplemented with $10 \%$ FCS and stimulated with $1 \mu \mathrm{g}$ of peptides IE $1 / \mathrm{m} 123\left({ }^{168} \mathrm{YPH}-\right.$ FMPTNL $\left.{ }^{176}\right)$, m164 $\left({ }^{257}\right.$ AGPPRYSRI $\left.^{265}\right)$, IE3 ( ${ }^{416}$ RALEYKNL $\left.^{423}\right)$, m139 $\left({ }^{419}\right.$ TVYGFCLL $\left.{ }^{426}\right)$, M45 $\left({ }^{985}\right.$ HGIRNASFI $\left.{ }^{993}\right)$, or M38 ( ${ }^{316}$ SSPPMFRV $\left.^{323}\right)$ for 6 hours at $37^{\circ} \mathrm{C}$, with brefeldin A (eBioscience) added for the last 4 hours of stimulation. For degranulation assays, CD107a mAb (D4B) and monensin (eBioscience) were added to the cultured cells during peptide stimulation. For DC population analysis, splenocytes were digested by collagenase D (Roche) as described previously (16). All samples were acquired by FACSAria (BD) and analyzed with FlowJo software (Tree Star). 
Sequence analysis of RAE-1 $\gamma$. Organ homogenates from $\mu \mathrm{MT} / \mu \mathrm{MT}$ B celldeficient mice with recurrent infection were serially diluted 2 -fold across 96-well trays and added to MEF cultures in 96-well trays. Wells showing a viral cytopathic effect derived from a single plaque were harvested for preparation of virus stocks. The RAE- $1 \gamma$ ORF was PCR amplified by using purified viral DNA. MEFs were infected with the recovered viruses, and whole genomic DNA was extracted using a DNeasy blood and tissue kit (QIAGEN). The region of interest was amplified by PCR with primers m152fw GTGTATGTGGCCCGACGGGCGG and m152rv CGCGGGCTACTCCCGAAAGAGTAACATC. The amplificate was sequenced (3130 genetic analyzer, Applied Bioscience) using the primers m152fw, GTGTATGTGGCCCGACGGGCGG, m152rv CGCGGGCTACTCCCGAAAGAGTAACATC, RAEfw ATGGCCAAGGCAGCAGTGAC, and RAErv TGCTCGACCTGAGGTAATTATAACCC. Sequences were aligned to the RAE- $1 \gamma$ ORF of the input virus using Vector NTI 11 (Invitrogen).

Quantification of MCMV-specific Ab and serum IFN- $\alpha$ levels by ELISA. Serum MCMV-specific IgG titers were determined by ELISA as previously described (93). Serum levels of IFN- $\alpha$ were determined by ELISA Kit for IFN- $\alpha$ (PBL Biomedical Laboratories) according to the manufacturer's instructions.

Statistics. Statistical significance was calculated by unpaired 2-tailed Student's $t$ test using Prism 4 software (GraphPad Software). Statistical analyses of the virus titers were done by Mann-Whitney $U$ test. $P$ values less than 0.05 were considered significant.

\section{Acknowledgments}

We thank Renata Grguric, Dijana Rumora, and Eduard Ražic for technical help. We thank Matthias J. Reddehase, Mirko Trilling, Luka Traven, and Jurica Arapovic for critically reading the manuscript. This study was supported by NIH grants 1R01AI083201-01 to S. Jonjic and 1R01NS065845-01 to W.J. Britt, National Foundation for Science, Higher Education and Technological Development of the Republic of Croatia grant $04 / 16$ to S. Jonjic and Croatian Ministry for Science and Technology grant 0621261-1268 to A. Krmpotic. A. Krmpotic is supported by the Howard Hughes Medical Institute International Research Scholars grant.

Received for publication June 8, 2010, and accepted in revised form September 22, 2010.

Address correspondence to: Stipan Jonjic, Department of Histology and Embryology, Faculty of Medicine, University of Rijeka, B. Branchetta 20, 51000 Rijeka, Croatia. Phone: 385.51.651.206; Fax: 385.51.651.176; E-mail: jstipan@medri.hr.
1. Pass RF. Cytomegalovirus. In: Knipe DM, Howley PM, eds. Fields Virology. 4th ed. Philadelphia, Pennsylvania, USA: Lippincott Williams and Wilkins; 2001:2675-2706.

2. Boppana SB, et al. Neuroradiographic findings in the newborn period and long-term outcome in children with symptomatic congenital cytomegalovirus infection. Pediatrics. 1997;99(3):409-414.

3. Boppana SB, Pass RF, Britt WJ, Stagno S, Alford CA. Symptomatic congenital cytomegalovirus infection: neonatal morbidity and mortality. Pediatr Infect Dis J. 1992;11(2):93-99.

4. Hamprecht K, Maschmann J, Vochem M, Dietz K, Speer CP, Jahn G. Epidemiology of transmission of cytomegalovirus from mother to preterm infant by breastfeeding. Lancet. 2001;357(9255):513-518.

5. Whitley RJ. Congenital cytomegalovirus infection: epidemiology and treatment. Adv Exp Med Biol. 2004;549:155-160.

6. Mwintshi K, Brennan DC. Prevention and management of cytomegalovirus infection in solidorgan transplantation. Expert Rev Anti Infect Ther. 2007;5(2):295-304.

7. Ljungman P. CMV infections after hematopoietic stem cell transplantation. Bone Marrow Transplant. 2008;42(suppl 1):S70-S72.

8. Streblow DN, Orloff SL, Nelson JA. Acceleration of allograft failure by cytomegalovirus. Curr Opin Immunol. 2007;19(5):577-582.

9. Steininger C, Puchhammer-Stockl E, PopowKraupp T. Cytomegalovirus disease in the era of highly active antiretroviral therapy (HAART). J Clin Virol. 2006;37(1):1-9.

10. Arvin AM, Fast P, Myers M, Plotkin S, Rabinovich R. Vaccine development to prevent cytomegalovirus disease: report from the National Vaccine Advisory Committee. Clin Infect Dis. 2004;39(2):233-239.

11. Krmpotic A, Bubic I, Polic B, Lucin P, Jonjic S. Pathogenesis of murine cytomegalovirus infection. Microbes Infect. 2003;5(13):1263-1277.

12. Koszinowski UH, Reddehase MJ, Jonjic S. The role of CD4 and CD8 T cells in viral infections. Curr Opin Immunol. 1991;3(4):471-475.

13. Reusser P, Riddell SR, Meyers JD, Greenberg PD. Cytotoxic T-lymphocyte response to cytomegalovirus after human allogeneic bone marrow transplantation: pattern of recovery and correlation with cytomegalovirus infection and disease. Blood. 1991;78(5):1373-1380.
14. Einsele H. Immunotherapy for CMV infection. Cytotherapy. 2002;4(5):435-436.

15. Peggs KS, et al. Adoptive cellular therapy for early cytomegalovirus infection after allogeneic stemcell transplantation with virus-specific T-cell lines. Lancet. 2003;362(9393):1375-1377.

16. Robbins $\mathrm{SH}$, et al. Natural killer cells promote early CD8 T cell responses against cytomegalovirus. PLoS Pathog. 2007;3(8):e123.

17. Rolle A, Olweus J. Dendritic cells in cytomegalovirus infection: viral evasion and host countermeasures. APMIS. 2009;117(5-6):413-426.

18. Reddehase MJ. Antigens and immunoevasins: opponents in cytomegalovirus immune surveillance. Nat Rev Immunol. 2002;2(11):831-844.

19. Polic B, et al. Hierarchical and redundant lymphocyte subset control precludes cytomegalovirus replication during latent infection. J Exp Med. 1998; 188(6):1047-1054

20. Jonjic S, Pavic I, Polic B, Crnkovic I, Lucin P, Koszinowski UH. Antibodies are not essential for the resolution of primary cytomegalovirus infection but limit dissemination of recurrent virus. J Exp Med. 1994;179(5):1713-1717.

21. Nigro G, Adler SP, La Torre R, Best AM. Passive immunization during pregnancy for congenital cytomegalovirus infection. N Engl J Med. 2005; 353(13):1350-1362.

22. Nigro G, et al. Regression of fetal cerebral abnormalities by primary cytomegalovirus infection following hyperimmunoglobulin therapy. Prenat Diagn. 2008;28(6):512-517.

23. Bratcher DF, et al. Effect of passive antibody on congenital cytomegalovirus infection in guinea pigs. J Infect Dis. 1995; 172(4):944-950.

24. Cekinovic D, et al. Passive immunization reduces murine cytomegalovirus-induced brain pathology in newborn mice. J Virol. 2008;82(24):12172-12180.

25. Chatterjee A, Harrison CJ, Britt WJ, Bewtra C. Modification of maternal and congenital cytomegalovirus infection by anti-glycoprotein b antibody transfer in guinea pigs. J Infect Dis. 2001;183(11):1547-1553.

26. Snydman DR, et al. Use of cytomegalovirus immune globulin to prevent cytomegalovirus disease in renal-transplant recipients. $N$ Engl J Med. 1987; 317(17):1049-1054

27. Schleiss MR. Cytomegalovirus vaccine development. Curr Top Microbiol Immunol. 2008;325:361-382.
28. Zhong J, Khanna R. Vaccine strategies against human cytomegalovirus infection. Expert Rev Anti Infect Ther. 2007;5(3):449-459.

29. Gonczol E, Plotkin S. Development of a cytomegalovirus vaccine: lessons from recent clinical trials. Expert Opin Biol Ther. 2001;1(3):401-412.

30. Griffiths P. The beginning of the end of a long wait for a vaccine against cytomegalovirus. Rev Med Virol. 2009;19(3):117-119.

31. Mohr CA, et al. A spread deficient cytomegalovirus for assessment of first target cells in vaccination. J Virol. 2010;84(15):7730-7742.

32. Pass RF, et al. Vaccine prevention of maternal cytomegalovirus infection. $N$ Engl J Med. 2009; 360(12):1191-1199.

33. Cicin-Sain L, et al. Targeted deletion of regions rich in immune-evasive genes from the cytomegalovirus genome as a novel vaccine strategy. J Virol. 2007;81(24):13825-13834.

34. Crumpler MM, Choi KY, McVoy MA, Schleiss MR. A live guinea pig cytomegalovirus vaccine deleted of three putative immune evasion genes is highly attenuated but remains immunogenic in a vaccine/ challenge model of congenital cytomegalovirus infection. Vaccine. 2009;27(31):4209-4218.

35. Lanier LL. NKG2D in innate and adaptive immunity. Adv Exp Med Biol. 2005;560:51-56.

36. Raulet DH. Roles of the NKG2D immunoreceptor and its ligands. Nat Rev Immunol. 2003;3(10):781-790.

37. Lisnic VJ, Krmpotic A, Jonjic S. Modulation of natural killer cell activity by viruses. Curr Opin Microbiol. 2010;13(4):530-539.

38. Arapovic J, Lenac Rovis T, Reddy AB, Krmpotic A, Jonjic S. Promiscuity of MCMV immunoevasin of NKG2D: m138/fcr-1 down-modulates RAE-1epsilon in addition to MULT-1 and H60. Mol Immunol. 2009; 47(1):114-122

39. Jonjic S, Polic B, Krmpotic A. Viral inhibitors of NKG2D ligands: friends or foes of immune surveillance? Eur J Immunol. 2008;38(11):2952-2956.

40. Wilkinson GW, et al. Modulation of natural killer cells by human cytomegalovirus. J Clin Virol. 2008; 41(3):206-212.

41. Ziegler H, et al. A mouse cytomegalovirus glycoprotein retains MHC class I complexes in the ERGIC/cisGolgi compartments. Immunity. 1997;6(1):57-66.

42. Krmpotic A, et al. MCMV glycoprotein gp40 confers virus resistance to CD8 $+\mathrm{T}$ cells and NK cells in 
vivo. Nat Immunol. 2002;3(6):529-535.

43. Reddehase MJ, Balthesen M, Rapp M, Jonjic S, Pavic I, Koszinowski UH. The conditions of primary infection define the load of latent viral genome in organs and the risk of recurrent cytomegalovirus disease. J Exp Med. 1994;179(1):185-193.

44. Jonjic S, Mutter W, Weiland F, Reddehase MJ, Koszinowski UH. Site-restricted persistent cytomegalovirus infection after selective long-term depletion of CD4+ T lymphocytes. J Exp Med. 1989; 169(4):1199-1212.

45. Campbell AE, Cavanaugh VJ, Slater JS. The salivary glands as a privileged site of cytomegalovirus immune evasion and persistence. Med Microbiol Immunol. 2008;197(2):205-213.

46. Balthesen M, Messerle M, Reddehase MJ. Lungs are a major organ site of cytomegalovirus latency and recurrence. J Virol. 1993;67(9):5360-5366.

47. Arase H, Mocarski ES, Campbell AE, Hill AB, Lanier LL. Direct recognition of cytomegalovirus by activating and inhibitory NK cell receptors. Science. 2002;296(5571):1323-1326

48. Smith HR, et al. Recognition of a virus-encoded ligand by a natural killer cell activation receptor. Proc Natl Acad Sci U S A. 2002;99(13):8826-8831.

49. Holtappels R, Bohm V, Podlech J, Reddehase MJ. CD8 T-cell-based immunotherapy of cytomegalovirus infection: "proof of concept" provided by the murine model. Med Microbiol Immunol. 2008; 197(2):125-134.

50. Holtappels R, Pahl-Seibert MF, Thomas D, Reddehase MJ. Enrichment of immediate-early 1 (m123/pp89) peptide-specific CD8 T cells in a pulmonary CD62L(lo) memory-effector cell pool during latent murine cytomegalovirus infection of the lungs. J Virol. 2000;74(24):11495-11503.

51. Wherry EJ, Ahmed R. Memory CD8 T-cell differentiation during viral infection. J Virol. 2004 78(11):5535-5545.

52. Andrews DM, et al. Innate immunity defines the capacity of antiviral $\mathrm{T}$ cells to limit persistent infection. J Exp Med. 2010;207(6):1333-1343.

53. Trgovcich J, et al. Immune responses and cytokine induction in the development of severe hepatitis during acute infections with murine cytomegalovirus. Arch Virol. 2000;145(12):2601-2618.

54. Reddehase MJ, Podlech J, Grzimek NK. Mouse models of cytomegalovirus latency: overview. J Clin Virol. 2002;25(suppl 2):S23-S36.

55. French AR, et al. Escape of mutant double-stranded DNA virus from innate immune control. Immunity. 2004;20(6):747-756.

56. Voigt V, et al. Murine cytomegalovirus m157 mutation and variation leads to immune evasion of natural killer cells. Proc Natl Acad Sci U S A. 2003; 100(23):13483-13488.

57. Presti RM, Pollock JL, Dal Canto AJ, O'Guin AK, Virgin HW IV. Interferon gamma regulates acute and latent murine cytomegalovirus infection and chronic disease of the great vessels. J Exp Med. 1998; 188(3):577-588.

58. Ogasawara K, Benjamin J, Takaki R, Phillips JH, Lanier LL. Function of NKG2D in natural killer cell-mediated rejection of mouse bone marrow grafts. Nat Immunol. 2005;6(9):938-945.

59. Erlach KC, Bohm V, Knabe M, Deegen P, Reddehase MJ, Podlech J. Activation of hepatic natural killer cells and control of liver-adapted lymphoma in the murine model of cytomegalovirus infection. Med
Microbiol Immunol. 2008;197(2):167-178.

60. Fowler KB, Stagno S, Pass RF. Maternal immunity and prevention of congenital cytomegalovirus infection. JAMA. 2003;289(8):1008-1011.

61. Boppana SB, Britt WJ. Antiviral antibody responses and intrauterine transmission after primary maternal cytomegalovirus infection. J Infect Dis. 1995; 171(5):1115-1121.

62. Boppana SB, Rivera LB, Fowler KB, Mach M, Britt WJ. Intrauterine transmission of cytomegalovirus to infants of women with preconceptional immunity. NEngl J Med. 2001;344(18):1366-1371.

63. Schleiss MR. Comparison of vaccine strategies against congenital CMV infection in the guinea pig model. JClin Virol. 2008;41(3):224-230.

64. Koontz T, et al. Altered development of the brain after focal herpesvirus infection of the central nervous system. J Exp Med. 2008;205(2):423-435.

65. Hansen SG, et al. Evasion of CD8+ T cells is critical for superinfection by cytomegalovirus. Science. 2010; 328(5974):102-106.

66. Gill TA, Morley PJ, Sweet C. Replication-defective mutants of mouse cytomegalovirus protect against wild-type virus challenge. J Med Virol. 2000; 62(2):127-139.

67. MacDonald MR, Li XY, Stenberg RM, Campbell AE, Virgin HW 4th. Mucosal and parenteral vaccination against acute and latent murine cytomegalovirus (MCMV) infection by using an attenuated MCMV mutant. J Virol. 1998;72(1):442-451.

68. Morello CS, Cranmer LD, Spector DH. In vivo replication, latency, and immunogenicity of murine cytomegalovirus mutants with deletions in the M83 and M84 genes, the putative homologs of human cytomegalovirus pp65 (UL83). J Virol. 1999; 73(9):7678-7693.

69. Snyder CM, Allan JE, Bonnett EL, Doom CM, Hill AB. Cross-presentation of a spread-defective MCMV is sufficient to prime the majority of virusspecific CD8+ T cells. PLoS One. 2010;5(3):e9681.

70. Holtappels R, Thomas D, Podlech J, Reddehase MJ. Two antigenic peptides from genes $\mathrm{m} 123$ and m164 of murine cytomegalovirus quantitatively dominate CD8 T-cell memory in the H-2d haplotype. J Virol. 2002;76(1):151-164

71. Karrer U, et al. Memory inflation: continuous accumulation of antiviral CD8+ T cells over time. J Immunol. 2003;170(4):2022-2029.

72. Karrer U, et al. Expansion of protective CD8+ T-cell responses driven by recombinant cytomegaloviruses. J Virol. 2004;78(5):2255-2264.

73. Hansen SG, et al. Effector memory $T$ cell responses are associated with protection of rhesus monkeys from mucosal simian immunodeficiency virus challenge. Nat Med. 2009;15(3):293-299.

74. Messerle M, Crnkovic I, Hammerschmidt W, Ziegler H, Koszinowski UH. Cloning and mutagenesis of a herpesvirus genome as an infectious bacterial artificial chromosome. Proc Natl Acad Sci US A. 1997;94(26):14759-14763.

75. Wagner M, Ruzsics Z, Koszinowski UH. Herpesvirus genetics has come of age. Trends Microbiol. 2002; 10(7):318-324.

76. Roizman B, Sears AE. An inquiry into the mechanisms of herpes simplex virus latency. Annu Rev Microbiol. 1987;41:543-571.

77. French AR, Pingel JT, Kim S, Yang L, Yokoyama WM. Rapid emergence of escape mutants following infection with murine cytomegalovirus in immuno- deficient mice. Clin Immunol. 2005;115(1):61-69.

78. Bohm V, et al. The immune evasion paradox: immunoevasins of murine cytomegalovirus enhance priming of CD8 $\mathrm{T}$ cells by preventing negative feedback regulation. J Virol. 2008;82(23):11637-11650.

79. Pinto AK, Munks MW, Koszinowski UH, Hill AB. Coordinated function of murine cytomegalovirus genes completely inhibits CTL lysis. J Immunol. 2006;177(5):3225-3234.

80. Krmpotic A, Messerle M, Crnkovic-Mertens I, Polic B, Jonjic S, Koszinowski UH. The immunoevasive function encoded by the mouse cytomegalovirus gene $\mathrm{m} 152$ protects the virus against $\mathrm{T}$ cell control in vivo. J Exp Med. 1999;190(9):1285-1296.

81. Munks MW, Pinto AK, Doom CM, Hill AB. Viral interference with antigen presentation does not alter acute or chronic CD8 T cell immunodominance in murine cytomegalovirus infection. J Immunol. 2007;178(11):7235-7241.

82. Del Val M, Schlicht HJ, Ruppert T, Reddehase MJ, Koszinowski UH. Efficient processing of an antigenic sequence for presentation by MHC class I molecules depends on its neighboring residues in the protein. Cell. 1991;66(6):1145-1153.

83. Jonjic S, Krmpotic A, Arapovic J, Koszinowski UH. Dissection of the antiviral NK cell response by MCMV mutants. Methods Mol Biol. 2008;415:127-149.

84. Wagner M, Jonjic S, Koszinowski UH, Messerle M. Systematic excision of vector sequences from the BAC-cloned herpesvirus genome during virus reconstitution. J Virol. 1999;73(8):7056-7060.

85. Wagner M, Gutermann A, Podlech J, Reddehase MJ, Koszinowski UH. Major histocompatibility complex class I allele-specific cooperative and competitive interactions between immune evasion proteins of cytomegalovirus. J Exp Med. 2002;196(6):805-816.

86. Zhang Y, Buchholz F, Muyrers JP, Stewart AF. A new logic for DNA engineering using recombination in Escherichia coli. Nat Genet. 1998;20(2):123-128.

87. Wagner M, Koszinowski UH. Mutagenesis of viral BACs with linear PCR fragments (ET recombination). Methods Mol Biol. 2004;256:257-268.

88. Brune W, Menard C, Hobom U, Odenbreit S, Messerle M, Koszinowski UH. Rapid identification of essential and nonessential herpesvirus genes by direct transposon mutagenesis. Nat Biotechnol. 1999; 17(4):360-364.

89. Hasan M, Polic B, Bralic M, Jonjic S, Rajewsky K. Incomplete block of B cell development and immunoglobulin production in mice carrying the muMT mutation on the BALB/c background. Eur J Immunol. 2002;32(12):3463-3471.

90. Krmpotic A, et al. NK cell activation through the NKG2D ligand MULT -1 is selectively prevented by the glycoprotein encoded by mouse cytomegalovirus gene m145. J Exp Med. 2005;201(2):211-220.

91. Wheat RL, Clark PY, Brown MG. Quantitative measurement of infectious murine cytomegalovirus genomes in real-time PCR. J Virol Methods. 2003;112(1-2):107-113.

92. Holtappels R, Janda J, Thomas D, Schenk S, Reddehase MJ, Geginat G. Adoptive CD8 T cell control of pathogens cannot be improved by combining protective epitope specificities. J Infect Dis. 2008; 197(4):622-629.

93. Jonjic S, Pavic I, Lucin P, Rukavina D, Koszinowski UH. Efficacious control of cytomegalovirus infection after long-term depletion of CD8+ T lymphocytes. J Virol. 1990;64(11):5457-5464. 